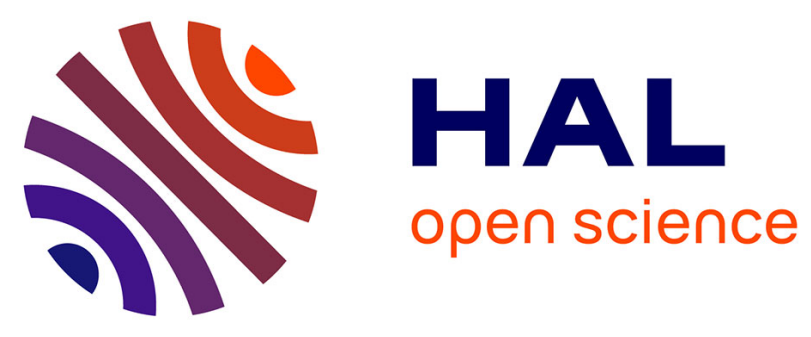

\title{
Clinical relevance of marginal factors on ultrafiltration in peritoneal dialysis
}

Sandra Sanz- Ballesteros, Vicente Pérez-Díaz, Alfonso Pérez-Escudero, Sandra

Sanz-Ballesteros, Luisa Sánchez-García, Esther Hernández-García, Victoria

Oviedo-Gómez, Alicia Sobrino-Pérez

\section{To cite this version:}

Sandra Sanz- Ballesteros, Vicente Pérez-Díaz, Alfonso Pérez-Escudero, Sandra Sanz-Ballesteros, Luisa Sánchez-García, et al.. Clinical relevance of marginal factors on ultrafiltration in peritoneal dialysis. Peritoneal Dialysis International, 2020, pp.089686082090455. 10.1177/0896860820904556 . hal03066135

\section{HAL Id: hal-03066135 https://hal.science/hal-03066135}

Submitted on 15 Dec 2020

HAL is a multi-disciplinary open access archive for the deposit and dissemination of scientific research documents, whether they are published or not. The documents may come from teaching and research institutions in France or abroad, or from public or private research centers.
L'archive ouverte pluridisciplinaire $\mathbf{H A L}$, est destinée au dépôt et à la diffusion de documents scientifiques de niveau recherche, publiés ou non, émanant des établissements d'enseignement et de recherche français ou étrangers, des laboratoires publics ou privés. 
Vicente Pérez-Díaz, Alfonso Pérez-Escudero, Sandra Sanz-Ballesteros, Luisa Sánchez-García, Esther Hernández-García, Victoria Oviedo-Gómez, Alicia Sobrino-Pérez. Clinical relevance of marginal factors on ultrafiltration in peritoneal dialysis. Perit Dial Int. In press. First Published on line February 12, 2020. https://doi.org/10.1177/0896860820904556

https://journals.sagepub.com/doi/full/10.1177/0896860820904556

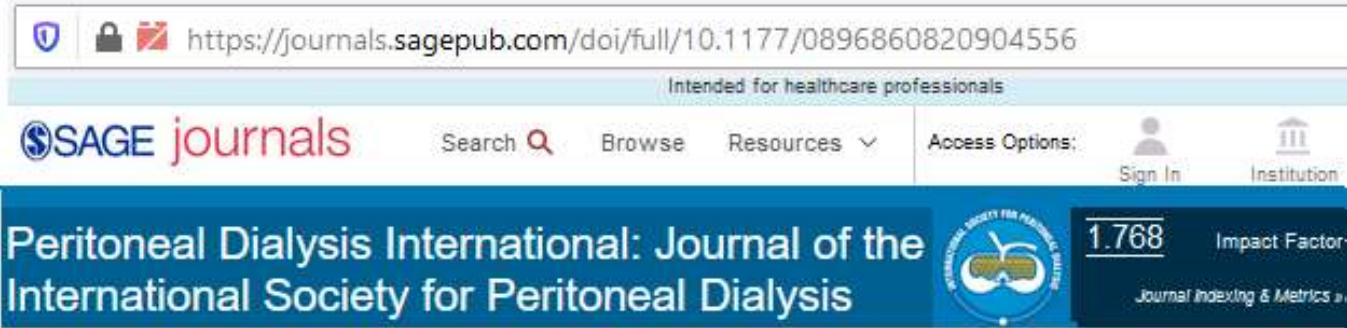

Journal Home Browse Journal $\vee$ Journal Info $\vee \quad$ Stay Connected $\vee \quad$ Submit Paper

Clinical relevance of marginal factors on ultrafiltration in peritoneal dialysis

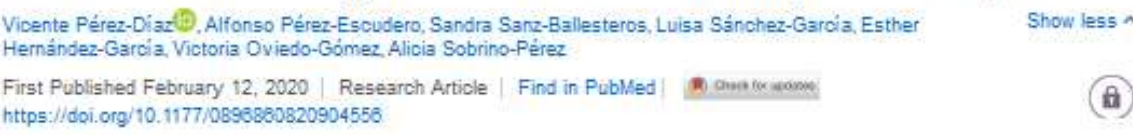

Abstract

Background:

Ultrafiltration (UF) in peritoneal dialysis (PD) is mainly driven by the osmotic gradient and peritoneal permeability, but other factors _ such as intraperitoneal pressure (IPP)_also have an influence.

Methods:

To assess the clinical relevance of these marginal factors, we studied 41 unselected PD patients undergoing two consecutive $2 \mathrm{~h}, 2.27 \%$ glucose exchanges, first with $2.5 \mathrm{~L}$ and then with $1.5 \mathrm{~L}$.

Results:

IPP, higher in the $2.5 \mathrm{~L}$ exchange, had a wide interpatient range, was higher in obese and polycystic patients and their increase with infusion volume was higher for women regardless of body size. UF with $2.5 \mathrm{~L}$ correlated inversely with $\mathrm{PP}$ and was higher for patients with polycystosis or hernias, while for 1.5 $\mathrm{L}$ we found no significant correlations. The effluent had higher glucose and osmolarity in the $2.5 \mathrm{~L}$ exchange than in the $1.5 \mathrm{~L}$ one, similar for both sexes. In spite of this stronger osmotic gradient, only 21 patients had more UF in the $2.5 \mathrm{~L}$ exchange, with differences up to $240 \mathrm{~mL}$. The other 20 patients had more UF in the $1.5 \mathrm{~L}$ exchange, with stronger differences (up to $800 \mathrm{~mL}$, and more than $240 \mathrm{~mL}$ for 9 patients). The second group, with similar effluent osmolarity and peritoneal equilibration test (PET) parameters than the first, has higher IPP and preponderance of men. The sex influence is so intense that men decreased average UF with $2.5 \mathrm{~L}$ with respect to $1.5 \mathrm{~L}$, while women increased it.

Conclusions:

With $2.27 \%$ glucose, sex and IPP—-modulated by obesity, polycystosis, hernias, and intraperitoneal volume -significantly affect UF in clinical settings and might be useful for its management.

Keywords

Gender, infusion volume, intraperitoneal pressure, obesity, peritoneal dialysis, ultrafiltration 


\section{Clinical relevance of marginal factors on ultrafiltration in peritoneal dialysis}

Authors: Vicente Pérez-Díaz $(\mathrm{MD}, \mathrm{PhD})^{1,2}$, Alfonso Pérez-Escudero $(\mathrm{PhD})^{3}$, Sandra SanzBallesteros $(\mathrm{MD}, \mathrm{PhD})^{1,2}$, Luisa Sánchez-García $(\mathrm{MD})^{4}$, Esther Hernández-García $(\mathrm{MD})^{5}$, Victoria Oviedo-Gómez (MD) ${ }^{5}$, Alicia Sobrino-Pérez (MD) ${ }^{1}$.

\section{Affiliations:}

${ }^{1}$ Department of Nephrology, Hospital Clínico Universitario de Valladolid, Spain.

${ }^{2}$ Department of Medicine, Dermatology and Toxicology. Universidad de Valladolid, Spain.

${ }^{3}$ Research Center on Animal Cognition (CRCA), Center for Integrative Biology (CBI), Toulouse University, CNRS, UPS, Toulouse 31062, France.

${ }^{4}$ Department of Nephrology, Hospital Universitario Rio Hortega de Valladolid, Spain.

${ }^{5}$ Department of Nephrology of Complejo Asistencial Universitario de Palencia, Spain.

Correspondence and requests for materials should be addressed to: Vicente Pérez-Díaz. Servicio de Nefrología. Hospital Clínico Universitario de Valladolid. Avenida Ramón y Cajal 3. 47003 Valladolid. Spain. Phone: +34 619591 281. Fax: +34 983257 511. E-mail: vperez5651@gmail.com.

\section{Supplemental material: 3 Figures, 3 Tables.}

\section{ABSTRACT}

Background: UF in PD is mainly driven by the osmotic gradient and peritoneal permeability, but other factors-such as intraperitoneal pressure (IPP)-also have an influence.

Methods: To assess the clinical relevance of these marginal factors, we studied 41 unselected PD patients undergoing two consecutive $2 \mathrm{~h}, 2.27 \%$ glucose exchanges, first with $2.5 \mathrm{~L}$ and then with 1.5L.

Results: IPP, higher in the 2.5L exchange, had a wide interpatient range, was higher in obese and polycystic patients and their increase with infusion volume was higher for women regardless of body size. UF with $2.5 \mathrm{~L}$ correlated inversely with IPP and was higher for patients with polycystosis or hernias, while for $1.5 \mathrm{~L}$ we found no significant correlations. The effluent had higher glucose and osmolarity in the $2.5 \mathrm{~L}$ exchange than in the $1.5 \mathrm{~L}$ one, similar for both sexes. In spite of this stronger osmotic gradient, only 21 patients had more UF in the $2.5 \mathrm{~L}$ exchange, with differences up to $240 \mathrm{~mL}$. The other 20 patients had more UF in the $1.5 \mathrm{~L}$ exchange, with stronger differences (up to $800 \mathrm{~mL}$, and more than $240 \mathrm{~mL}$ for 9 patients). The second group, with similar effluent osmolarity and PET parameters that the first, has higher IPP and preponderance of men. The sex influence is so intense that men decreased average UF with $2.5 \mathrm{~L}$ with respect to $1.5 \mathrm{~L}$, while women increased it. 
Conclusions: With $2.27 \%$ glucose, sex and IPP - modulated by obesity, polycystosis, hernias and IPV - significantly affect UF in clinical settings, and might be useful for its management.

Keywords: Peritoneal dialysis; ultrafiltration; intraperitoneal pressure; infusion volume; obesity; gender.

\section{INTRODUCTION}

Insufficient ultrafiltration (UF) in peritoneal dialysis (PD) patients restrict their diet, worsens their prognosis and causes additional pathology. In order to stimulate UF, clinicians modify the composition of PD solutions or the dwell time, according to each patient's peritoneal permeability $(1,2)$. Infusion volume or other parameters of the procedure are ignored when handling UF issues. The reason is that, while UF is affected by many factors besides the osmotic gradient and peritoneal permeability (3), they are thought to be too weak to be relevant in daily clinical practice.

This work studies whether intraperitoneal pressure (IPP) and related factors influence UF in the daily practice of PD. To do this we compare in not selected PD patients two high-UF exchanges with different IPP.

\section{PATIENTS AND METHODS}

We studied all adult patients from three PD units who had remained stable for more than 2 months (no infectious events or significant hemodynamic or hepatic dysfunction), and without other restrictions. We recorded sex, age, weight, height, body surface (Mosteller

formula: $\sqrt{H W} / 360$, where $H$ is height in $\mathrm{m}$ and $W$ is weight in $\mathrm{kg}$ ), body mass index (BMI) $\left(W / H^{2}\right)$, presence of polycystic kidney disease and/or non-functioning renal graft, presence of parietal and/or hiatal hernias, months in PD, Charlson comorbidity score, ultrasensitive Creactive protein (CRP), parameters from closest PET $2 \mathrm{~L}, 4 \mathrm{~h}, 3.86 \%$, (D/Purea, D/Pcreatinine, D/D0glucose and UF; all PET's performed within 6 months of our study). We noted the use of diuretics, ACEi-ARB, corticosteroids or beta-blockers.

The procedure was performed in the PD unit by the usual nurse and consisted of performing, without prior special preparation, two consecutive exchanges of $2 \mathrm{~h}$ with $2.27 \%$ glucose, the first with $2.5 \mathrm{~L}$ and the second with $1.5 \mathrm{~L}$ (Figure $1 \mathrm{~A}$ ). All drainages were thoroughly completed using the most effective maneuvers for each patient. Volumes were measured by weight $(1 \mathrm{~mL}=1 \mathrm{~g})$. To maximize IPP differences, during the first exchange $(2.5 \mathrm{~L})$ the patients remained upright and normally active; during the second exchange (1.5L) the patients remained in bed rest. 


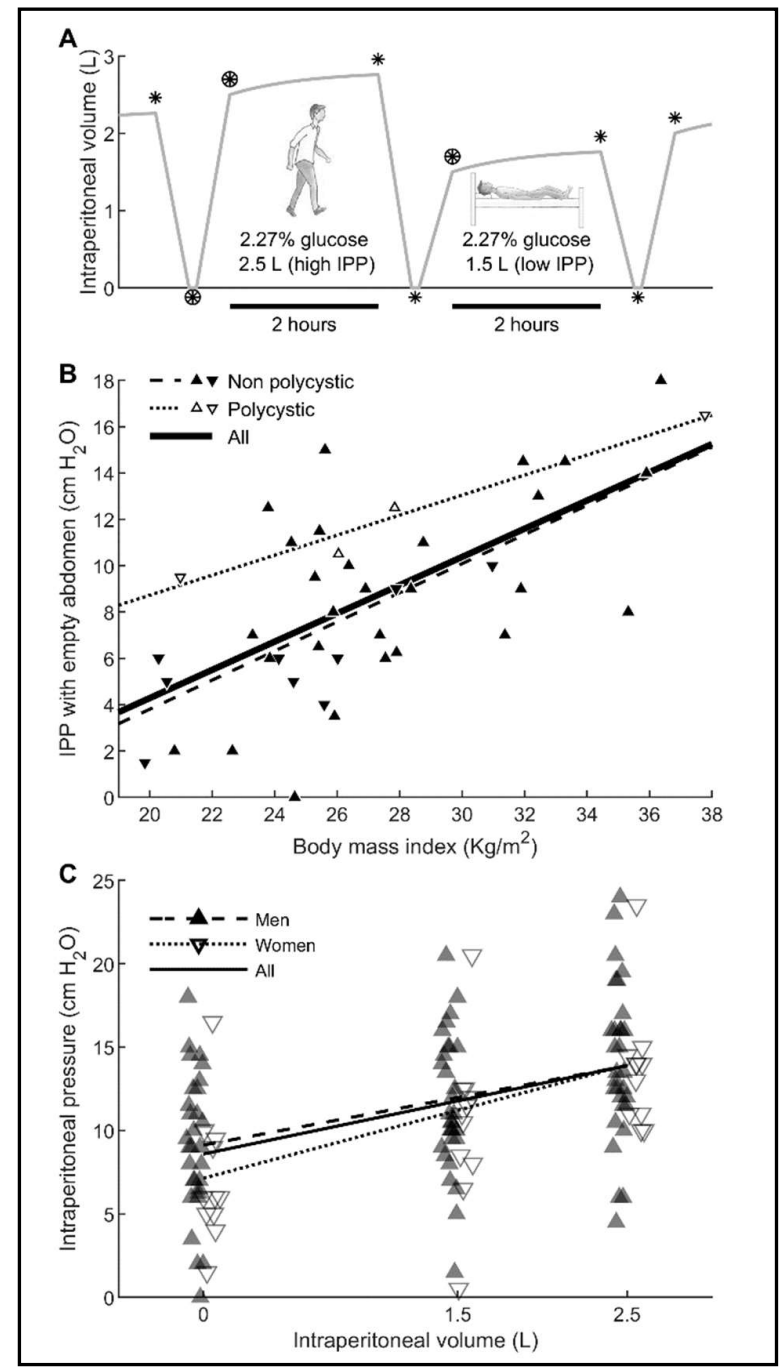

Figure 1.- A.- Experimental design. Circled asterisk: Principal measurements of intraperitoneal pressure (IPP): empty abdomen, 1.5L and 2.5L. Asterisk: other IPP measurements. B.- Intraperitoneal pressure increases with body mass index $(p<0.00001)$ and is higher for polycystic patients $(\triangle \nabla)(p=0.046)$. The slopes of the three lines are not significantly different $(p=0.5)$. IPP was the same for men $(\boldsymbol{\Delta} \triangle)$ and women $(\boldsymbol{\nabla} \nabla)(p=0.2)$. C.- Intraperitoneal pressure increases with intraperitoneal volume $\left(p<10^{-10}\right)$, faster in women $(\nabla)$ than in men $(\boldsymbol{\Delta})(p=0.006)$.

IPP was measured in strict decubitus and rest before and after each infusion or drainage (Figure $1 \mathrm{~A}$ ), by means of a central venous pressure system connected to a 3-way connector located between the peritoneal catheter and the PD bag (4-6). After checking respiratory oscillation, the intermediate point of a normal excursion was noted. Three measurements of IPP with empty abdomen (void IPP) and six with peritoneal solution were taken (Figure 1A). 7 patients, who arrived and left the procedure with an empty abdomen did not undergo the first and last IPP measurements shown in Figure 1A. Each IPP measurement was associated with an IPV equal to the volume of the nearest drainage or infusion. 
The values of the 3 void measurements were very similar $(8.6 \pm 4.2,7.7 \pm 4.3$ and $8.4 \pm 4.3$ $\mathrm{cmH} 2 \mathrm{O})$ and very different from those obtained after infusing $1.5 \mathrm{~L}(11.2 \pm 4.3 \mathrm{cmH} 2 \mathrm{O})$ and $2.5 \mathrm{~L}$ $(14 \pm 4.4 \mathrm{cmH} 2 \mathrm{O})(p<0.0001$ between any of the 3 volumes). Most variables that correlated with void IPP also correlated with IPP at the beginning or end of any of the two exchanges, although correlations were generally better with the void IPP. Therefore, the first of the void IPPs in the procedure was taken as baseline IPP, and all comparisons and correlations are referred to it unless otherwise specified. IPP at the beginning of the $1.5 \mathrm{~L}$ and $2.5 \mathrm{~L}$ exchanges was taken as representative of each volume.

As controls for the anthropometric data, we used 951 asymptomatic patients who participated in a study to prevent recurrence of renal lithiasis.

Treatment protocol complied with the Declaration of Helsinki and was approved by the Ethics Committee of Clinical Investigation of Area de Salud Valladolid- Este (CEIC-VA-ESTE-HCUV) (PI 16 - 348 CINV 15 - 78) and the Research Committee of the Hospitals Clínico Universitario de Valladolid, Río Hortega de Valladolid and Complejo Asistencial Universitario de Palencia, Spain. Patients provided their written informed consent before being treated.

All values are reported as mean \pm standard deviation, unless otherwise specified. Statistical analysis was performed using Excel software, version Office 365 (Microsoft) and Matlab 2019a (Mathworks). Comparisons of means of continuous variables were performed with independent or paired Student's $t$-tests (we checked that all conclusions remained unchanged when doing non-parametric bootstrap $t$-tests). All tests were 2-sided, and results with $p<0.05$ were considered statistically significant. Qualitative or dichotomic variables were compared with the chi-square test or Fisher's exact test.

To find factors that predict IPP and UF we used stepwise linear models (using Matlab's function stepwiselm). This method starts from a constant model and adds predictors one by one: In each round the most descriptive predictor is added, as long as its contribution to the overall fit is statistically significant (at the 0.05 level).

To find factors that predict compliance, we first fitted all IPP and IPV data for each patient to a line, extracting one slope per patient (the statistics for these slopes are shown in Table 1 and Supplemental Table 0-S). Then we used a linear model to find variables that predict these slopes, as described in the previous paragraph.

\section{RESULTS}

We recruited 41 adult PD patients (11 women, 6 of them with previous pregnancies), aged 37 to 81 years. Four patients were polycystic ( 2 men), 7 (6 men) had hernias (all of them umbilical and diagnosed after the initiation of PD), and 2 of these patients ( 1 man) suffered both. 
Body mass index (BMI) had a wide range, similar between men and women (Table 1) and to our control group. A PET 4h/3.86\% 2L was available for 31 patients ( 23 men); 5 ( 5 men) had averagelow peritoneal transport characteristics $(0.50<\mathrm{D} /$ Pcreatinine<0.68), 21 (15 men) average-high $(0.68<\mathrm{D} /$ Pcreatinine $<0.82)$ and $5(3 \mathrm{men})$ high $(0.82<\mathrm{D} /$ Pcreatinine $<1.01)$. Blood glucose at $2 \mathrm{~h}$ was $126 \pm 45 \mathrm{mg} / \mathrm{dL}, 76-286 \mathrm{mg} / \mathrm{dL}$ for these 31 patients.

Void IPP was $8.6 \pm 4.2 \mathrm{~cm} \mathrm{H}_{2} \mathrm{O}$, ranging between 0 and $18 \mathrm{~cm} \mathrm{H}_{2} \mathrm{O}$ (Table 1). Void IPP increased with BMI (at $0.6 \pm 0.1 \mathrm{~cm} \mathrm{H} \mathrm{H}_{2} \mathrm{O}$ per $\mathrm{kg} / \mathrm{m}^{2}, r=0.66, p=0.000003$ ), and was higher for patients with polycystosis (on average $3.4 \mathrm{~cm} \mathrm{H}_{2} \mathrm{O}$ higher, $p=0.046$ ) (Figure 1B). We found no significant correlation with any other factor (in particular, there was no correlation with height, $p=0.8$ ). IPP with $1.5 \mathrm{~L}$ was $11.2 \pm 4.3 \mathrm{cmH}_{2} \mathrm{O}$, and with $2.5 \mathrm{~L}$ was $14.0 \pm 4.4 \mathrm{cmH}_{2} \mathrm{O}$ (Table 1). IPP was significantly different across the three conditions (empty abdomen and the two infusion volumes, $p<0.0001$ for every pair of comparisons). IPP increased when increasing IPV at $2.12 \pm 0.86 \mathrm{cmH}_{2} \mathrm{O} / \mathrm{L}$ (range -0.07 to $4.92 \mathrm{cmH}_{2} \mathrm{O} / \mathrm{L}$ ) (Table 1, Figure 1C). Sex differences in IPP were not statistically different for any individual volume $(p>0.18$, Tables 1 and 2$)$, but the increase in IPP with IPV was significantly slower in men, than in women ( $p=0.006)$ (Table 1, Figure 1C). Height and body surface also show significant correlations with the rate of increase of IPP with IPV ( $p=0.03$ for both), but these correlations disappear when correcting for sex, which is a better predictor ( $r=0.4$ for sex vs. $r=0.3$ for height or body surface). There was no significant difference between the IPP at the beginning and end of each exchange (14.0 \pm 4.4 and $13.4 \pm 5.1$ $\mathrm{cmH}_{2} \mathrm{O}$ with 2.5L; $11.2 \pm 4.3$ and $11.7 \pm 4.0 \mathrm{cmH}_{2} \mathrm{O}$ with $1.5 \mathrm{~L} ; p>0.1$ for both) with IPV differences of $128 \pm 207 \mathrm{~mL}$ and $195 \pm 145 \mathrm{~mL}$ respectively.

Effluent glucose concentration and osmolarity were significantly higher for the highvolume exchange than for the low-volume one $(p<0.001)$, and equal for men and women in both exchanges (Table 2). Net UF was lower in the high-volume exchange than in the low-volume one, although the difference did not reach statistical significance $(p=0.09)$. However, men had significantly higher UF in the low-volume exchange than in the high-volume one ( $p=0.01)$, while women showed the opposite trend ( $p=0.01$ ) (Table 2, Figure 2A). The difference in UF between both exchanges was significantly different for men and women $(p=0.01)$ (Table 1$)$. This sex difference cannot be explained by body size ( $p>0.1$ for the correlations between difference in UF between the two exchanges and height, weight, or a combination of both). Neither can it be explained by differences in PET parameters or polycystosis $(p>0.2$ for all factors on their own; $p>0.05$ for all factors when combined in the same linear model).

UF in the low-volume exchange did not correlate significantly with any of the parameters recorded in the experiment. In contrast, for the high-volume exchange UF correlated negatively with IPP (UF decreased $24 \pm 6 \mathrm{~mL}$ per each $\mathrm{cm} \mathrm{H}_{2} \mathrm{O}$ of increase in IPP, $p=0.0006$ ), and positively 
with presence of polycystosis (which increased UF by $290 \pm 90 \mathrm{~mL}$ higher on average, $p=0.002$ ), and presence of hernias (which increased UF by $170 \pm 60 \mathrm{~mL}, p=0.02$ ) A linear model accounting for all these factors achieves $r=0.62$ (Figure $2 \mathrm{~B}$ ). These trends maintain the same sign and similar magnitude when splitting the data between men and women, although most of them lose statistical significance due to the low sample size. There was no significant correlation with any other factor (in particular, we found no correlation with the parameters from PET, $p>0.25$ in all cases).

Only 21 patients (51\%) increased UF when increasing IPV from 1.5 to $2.5 \mathrm{~L}$ (for these patients the increase was $110 \pm 68 \mathrm{~mL}$, range 16 to $240 \mathrm{~mL}$ ). The other 20 patients $(49 \%)$ decreased UF by $-254 \pm 240 \mathrm{~mL}$ (range -15 to $-800 \mathrm{~mL}$ ). Nine of these patients, all men, decreased UF by more than $240 \mathrm{~mL}$ ( 250 to $800 \mathrm{~mL}$ ) (Figure 3). When comparing the patients for whom UF decreases with IPV and those for whom it increases, we found two significant factors (Figure 3B): First, most women (82\%) increase UF with IPV, while most men (60\%) decrease it ( $p=0.03)$. Second, patients that decrease UF with IPV have higher IPP $(p=0.02)$. We found no significant differences in any other parameter. In particular, both groups had similar parameters of transport in PET 3.86\%, similar distribution of patients with medium-low (1 vs 4), medium-high (11 vs 10) and high ( 2 vs 3) permeability, and the same glucose concentration and osmolarity at the end of both exchanges (Figure 3B).

We represented the difference in UF between the two exchanges as a function of IPP, finding a significant correlation ( $p=0.02)$ and sex dependence $(p=0.02)$ (Figure $2 C)$. This effect of sex is mainly an upward shift, since the slopes for both sexes are not significantly different $(p=0.7)$.

\section{DISCUSSION}

Clinicians manage UF in PD almost exclusively through the transperitoneal osmotic gradient, by modifying dwell time or the type and concentration of the solutions $(1,2)$. Many other factors are known to modulate UF (3), but they are considered clinically irrelevant to solve UF problems. One of these factors is IPP (6-15), which opposes UF by enhancing diffusion of peritoneal contents to the surrounding tissues such as muscles, increasing lymphatic absorption, and reducing transcapillary filtration as reviewed in (16). This effect is however neglected in clinical practice, being considered a slight opposition to the strong suction of the osmotic gradient (13). No studies demonstrate the clinical relevance of IPP on UF in PD, and we only find indirect evidence evaluating UF with different volumes $(13,17-20)$, changes in body position (21) or in special situations such as Steady Concentration Peritoneal Dialysis (22). We designed this study to test whether IPP can have a significant impact on UF in standard clinical conditions. 


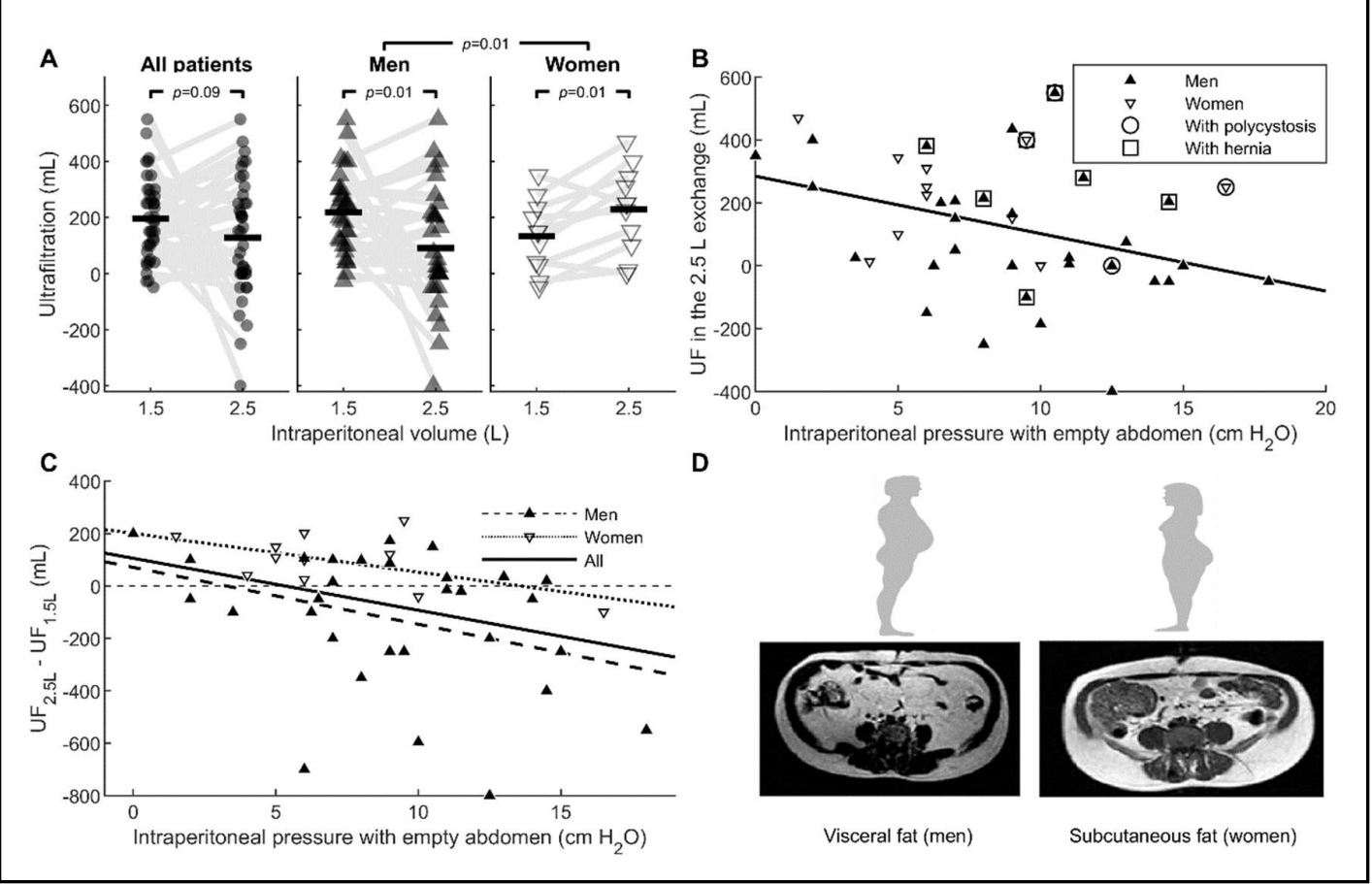

Figure 2.- A.- By increasing infusion volume from $1.5 \mathrm{~L}$ to $2.5 \mathrm{~L}$, net UF tend to decrease $(p=0.09)$. But by sex, in men UF decreases significantly $(p=0.01)$, while in women increases significantly $(p=0.01)$. B.- UF with $2.5 \mathrm{~L}$ decreases when intraperitoneal pressure increases $(p=0.0006)$ and is higher in patients with polycystosis $(p=0.002)$ or hernia $(p=0.002)$. C.- The difference between UF in the $2.5 \mathrm{~L}$ and $1.5 \mathrm{~L}$ exchanges, vs IPP, show that women and patients with low IPP tend to have more UF with low intraperitoneal volume. Lines of best fit for men and women have slopes not different $(p=0.7)$ with a significant upwards shift for women $(p=0.022)$. D.- Magnetic resonance images of a BMI-matched male and female. In men adipose tissue preferentially accumulates in the visceral depot while fat accumulation is primarily in the subcutaneous depot in women. Modified from (40) with permission.

Our protocol aimed to compare in normal adult PD patients two exchanges with different IPP's, but in all other aspects as similar as possible to each other and to standard PD conditions. Both exchanges were performed with $2.27 \%$ glucose in 2 hours in order to generate abundant UF. We used IPV to modulate IPP, performing one exchange with $1.5 \mathrm{~L}$ infusion volume and another one with $2.5 \mathrm{~L}$. These sets of concentration, IPV and dwell times are not unusual in clinical practice in automated PD, where volumes are prescribed without monitoring IPP, patient discomfort being the only indicator of intolerance. External abdomen compression also increases IPP (6), but we did not use it because it would deviate too much from standard PD procedures. IPP also changes with posture and activity, being lower in supine and rest, and higher when standing, sitting, or performing exercise $(4,5)$. We used this fact to increase the difference in IPP between both exchanges, keeping patients in bed during the low-volume exchange and asking them to stand up and perform normal activities during the high-volume exchange. All measurements of IPP were however performed with patients in supine, so 
measured IPP's are probably closer to their actual value during the low-volume exchange than during the high-volume one. The two exchanges were consecutive, the high-volume exchange always going first, because our previous study showed that severe overhydration can increase UF (22). Our exchanges (done with $2.27 \%$ glucose) are likely to reduce overhydration, so we expected a bias towards higher UF in the first exchange. To prevent any excess of UF in the lowvolume exchange from being attributed to this bias, we always performed the low-volume exchange in second place. We measured IPP with a central venous pressure system (4-6), which allows measuring IPP with empty abdomen and is more accurate than Durand's method (in fact Durand used it as gold-standard to validate his method) (23).

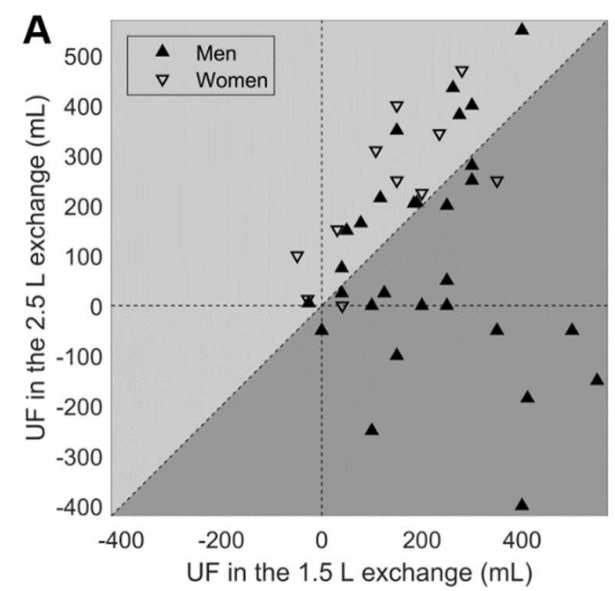

\begin{tabular}{lccc} 
B & $\begin{array}{c}\text { Patients that } \\
\text { increase } \\
\text { UF with IPV } \\
(n=21)\end{array}$ & $\begin{array}{c}\text { Patients that } \\
\text { decrease } \\
\text { UF with IPV } \\
(n=20)\end{array}$ & $p$ \\
\hline Glucose 2.5L (mg/dL) & $1101 \pm 128$ & $1057 \pm 159$ & 0.5 \\
Glucose 1.5L (mg/dL) & $1012 \pm 196$ & $921 \pm 143$ & 0.1 \\
Osmolarity 2.5L (mOs/L) & $331 \pm 7$ & $335 \pm 7$ & 0.1 \\
Osmolarity 1.5L (mOs/L) & $325 \pm 8$ & $326 \pm 6$ & 0.6 \\
\hline D/P creatinine & $0.71 \pm 0.09$ & $0.76 \pm 0.05$ & 0.07 \\
D/P urea & $0.90 \pm 0.05$ & $0.92 \pm 0.04$ & 0.1 \\
D/D0 glucose & $0.29 \pm 0.08$ & $0.28 \pm 0.06$ & 0.7 \\
UF PET (mL/4h) & $642 \pm 202$ & $645 \pm 260$ & 0.97 \\
\hline IPP (cmH $\mathbf{0})$ & $7.1 \pm 3.6$ & $10.2 \pm 4.2$ & $\mathbf{0 . 0 2}$ \\
Sex ratio (M/ W) & $12 / 9$ & $18 / 2$ & $\mathbf{0 . 0 3}$ \\
\hline & & & \\
\hline
\end{tabular}

Figure 3. Clinical impact. Half of the patients increase UF when decreasing IPV. A.- UF in the 2.5 $L$ exchange versus UF in the $1.5 \mathrm{~L}$ exchange. Patients that increase UF when increasing IPV (as would be predicted by the stronger osmotic gradient) fall on the upper triangle. Patients that decrease UF when increasing IPV fall on the lower triangle. B. Table showing the statistics of both groups of patients, and the $p$-values for the comparison between both groups (Student's unpaired $t$-test for all variables except for sex ratio; Fisher's exact test for sex ratio). Both groups have similar peritoneal osmolarity and permeability but differ in sex and IPP.

Our measurements of IPP agree with those reported for PD patients, both with empty abdomen $(24,25)$ and with different infusion volumes (24-26) (although some authors report mean values of $19(15,27,28)$ and even up to $49 \mathrm{cmH}_{2} \mathrm{O}(29)$ with $2 \mathrm{~L}$ infusion volume). This agreement with the literature applies both to the mean values and to the wide interpatient range found $(15,24,30,31)$. Two factors seem to contribute to this interpatient variability: First, IPP was higher in patients with polycystosis ( $p=0.045$; a stronger significance could not be expected, given that only 4 patients have polycystosis). This relationship, although not explicitly described in the literature, is assumed by authors who discuss the frequent association between polycystosis and hernias $(32,33)$-an association also present in our data. Second, IPP increases with obesity (BMI, but not height), a well-known relation $(15,24,28,30,31,34)$. The wide variation 
in obesity in our patients (BMI 19.8 to $37.8 \mathrm{~kg} / \mathrm{m}^{2}$ ) thus explains around $25 \%$ of the interpatient variability in IPP. No other factor correlated with IPP; in particular we found no difference in IPP between men and women (Table 1). In sum, our patients have normal IPP's, spread over a wide range, equal for both sexes, higher in polycystic patients, and linked to obesity.

As expected, IPP was higher during the high-volume exchange than during the lowvolume one. Our data show that IPP increases with IPV at $2.12 \pm 0.86 \mathrm{cmH}_{2} \mathrm{O} / \mathrm{L}$, a rate consistent with the literature $(4,24,35,36)$ The rate of increase of IPP with IPV was faster for women ( $p=0.006$, Table 1, Figure $1 C)$, a difference not justified by the different body size of men and women. Therefore, other factors that differ across sexes probably affect compliance.

Increasing IPV slows down the equilibration of dialysate-plasma concentrations (13,37), increasing the average glucose concentration during the exchange. This increase should translate into higher UF, but only studies using $3.86 \%$ glucose find a consistent increase in UF with IPV (13); this increase is less clear for $2.27 \%$ glucose $(17,29)$ and inconsistent for $1.36 \%$ glucose, where some studies show an increase of UF with IPV (18), and others show a decrease (19). Efforts to clarify the question have considered an effect of IPP at high volumes, especially with low osmotic gradient $(13,38)$. Others introduce obesity into the equation (29). However, in view of the inconsistency, the current consensus is to not consider IPV in relation to UF issues, which are handled by modulating only dialysate glucose concentration and dwell time $(1,2)$. We designed our study to clarity to this topic. We found that final osmolarity and glucose concentration were higher for the high-volume exchange, as expected. But these higher concentrations did not lead to higher UF, which in fact was lower for the high-volume exchange. Although the decrease is not statistically different $(p=0.09$, Table 2$)$, the absence of increase is very relevant clinically: In our 2 exchanges with a potent as $2.27 \%$ glucose concentration, the exchange with highest IPP was also the one with higher final glucose concentration; the effect of IPP was powerful enough to prevent this exchange from having higher final UF, even making it lower. Splitting our patients by sex uncovered an even more intriguing trend: Even though IPP and osmolarity increase in the same way for men and women when increasing IPV (Table 2), their UF follows opposite trends: UF increases significantly when increasing IPV in women $(p=0.01)$, while it decreases significantly in men ( $p=0.01)$ (Figure $2 \mathrm{~A}$, Table 2$)$. This result suggests that women are less sensitive than men to the effects of IPP, but we found this to be false (Figure $2 \mathrm{C}$, discussed below). In any case, this difference, added to the one in compliance, raises the question of what causes these differences across sexes, while giving us a new factor to predict the implications on UF of changing IPV in PD.

When looking for factors that predict UF in each exchange, we only found significant correlations for the high-volume exchange: UF decreases with IPP ( $p=0.0005)$, and is higher for 
patients with polycystosis $(p=0.02)$ and in patients with hernias $(p=0.03)$. These correlations seem to be similar for both sexes, although we cannot be sure due to our small sample size. The correlation with IPP confirms its known influence on UF, and the fact that we only find it for the high-IPV exchange is consistent with previous works indicating that stronger osmotic gradients require higher IPPs to show an effect on UF (reviewed in (16)). In the present study, done with $2.27 \%$ glucose solution, the effect of IPP is evident only with $2.5 \mathrm{~L}$. Perhaps with $1.36 \%$ glucose the effect of IPP on UF would be evident with smaller IPV's, while with $3.86 \%$ glucose even higher IPV's might be needed. Patients with polycystosis and/or hernias had high UF, even though they had the same effluent osmolarity and slightly higher IPP than patients without these conditions. We do not find an explanation to this finding, which should be confirmed with a larger group of patients, as it might be an artifact due to our limited sample size.

Again, the strongest indication of the clinical relevance of marginal factors is the large proportion of patients who decrease UF when increasing IPV (Figure 3). We would expect higher UF in the high-volume exchange due to the stronger osmotic gradient, but only half of the patients (21/41) showed this expected increase. Furthermore, the increase in UF for these 21 patients is moderate (up to $240 \mathrm{~mL}$ ), while the decrease for the other 20 patients is stronger (up to $800 \mathrm{~mL}$, and more than $240 \mathrm{~mL}$ for 9 patients) (Figure 3). When we compared the two groups of patients with opposite trends (Figure 3B), we found that both groups have similar characteristics of peritoneal permeability and similar final osmolarity and glucose concentration in the effluent in both exchanges. In contrast, they differ in their IPP and sex: The 20 patients whose UF decreases when increasing IPV have higher IPP $(p=0.02)$ and are almost all men $(18 \mathrm{~m}$ / $2 \mathrm{w} ; p=0.03)$.

Even though they have similar IPP as men, women tend to increase their UF when increasing IPV. This finding suggests that women are less sensitive than men to the effects of IPP, and to test this hypothesis we studied how the difference in UF between the two exchanges changes as a function of void IPP for men and women. The rate of change seems to be the same for both sexes, the difference between them being an upward shift in the difference in UF for women (Figure 2C). Therefore, while IPP has a similar effect in both sexes, women seem to need a higher IPP to revert the effect of the osmotic gradient.

The differences between men and women cannot be explained solely by their different body size nor by other factors such as PET parameters or polycystosis-other characteristics linked to sex must be contributing, and the nature of our results suggests anatomical factors. A possible candidate is the distribution of body fat, which differs across sexes (39): While in men the excess of fat accumulates intraperitoneally, in women fat typically accumulates in the subcutaneous panniculus (Figure 2D). Another possibility (A.K. Al-Whiesh, personal suggestion) 
could be in the abdominal anatomical-physiological differences that could mark previous pregnancies. Differentiating in our 11 women those who had $(n=6)$ or not $(n=5)$ previous pregnancies, we saw that women with previous pregnancies have more comorbidity $(p=0.05)$ than those without a history of pregnancy (Supplemental material table 1-S). The difference in compliance (increase in IPP with increasing IPV) between men and women is mainly due to women without previous pregnancies $(p=0.002)$, who have a lower compliance than pregnant women (for every liter of IPV the IPP increases $3.2 \pm 1.1 \mathrm{cmH}_{2} \mathrm{O}$ compared to $2.3 \pm 0.4 \mathrm{cmH}_{2} \mathrm{O}$ for those who had pregnancies and $1.9 \pm 0.8 \mathrm{cmH}_{2} \mathrm{O}$ for men $(p=0.002$ among women without pregnancies and men). In addition, women with previous pregnancies have lower UF with $1.5 \mathrm{~L}$ than those who had no history of pregnancies ( $42 \pm 77$ vs $243 \pm 76 \mathrm{~mL}, p=0.002)$ and also, although not significant, with $2.5 \mathrm{~L}(163 \pm 162 \mathrm{vs} 308 \pm 101 \mathrm{~mL} p=0.12)$ (Supplemental material table 1-S). However, the UF's response to the increase in IPP is the same in women with and without previous pregnancies; both groups increase UF when increasing IPV, unlike the men who decrease it (Supplemental material table 2-S, figs 3-S and 4-S). In addition, both groups of women are sensitive to IPP needing IPP levels higher than men (Supplemental material fig 2CS). Our few cases thus confirm that the history of previous pregnancies makes a difference that can modify the compliance but does not explain the different reaction of UF to the increase in IPP. Further studies will be needed to determine the causes underlying the different behavior of UF with IPP and IPV in men and women.

Our study has several limitations. We only study exchanges with $2.27 \%$ glucose, and dwell times of 2 hours. We could only recruit a limited number of patients from several centers, limiting the statistical power of our analyses. This statistical power is further limited when comparing with PET, which was available only for 31 patients. The effect of overhydration, which was relevant in a previous study (22), has not been assessed in our experiment. The different posture and activity in the two exchanges was intended to increase the differences in IPP, but also modifies liquid distribution, decreasing the area of contact $(21,40)$. These effects are however minimized at high volumes, $(2.5 \mathrm{~L}$ in our patients). Furthermore, previous studies found no or little effect of posture on net UF $(21,40)$. The ordering of exchanges, which intended to produce a bias which should favor UF in the high-volume exchange and strengthen our conclusions (22), may also introduce other unwanted biases. Our protocol did not include blood tests, which was only performed in 10 patients when the test coincided with their clinical review (glucose $112 \pm 13 \mathrm{mg} / \mathrm{dL}, 82-165 \mathrm{mg} / \mathrm{dL}$ ). While this is a limitation of our study, the moderate blood glucose levels in the PET of these patients do not suggest a significant influence on the final glucose concentrations in the dialysate. Finally, although we took special care to fully drain 
in all cases, residual volume was not estimated and could alter UF measurements for both exchanges.

We have shown that factors other than the concentration gradient can cause changes in UF so important as to counteract the effect of $2.27 \%$ glucose in the usual PD conditions; this suggests that these factors may precipitate or aggravate situations of fluid overload or, used to our advantage, help us in their prevention or treatment. Until now we only had two tools to modify UF in PD: the composition of the solutions and the dwell time; this paper adds the notion of the importance of IPP, BMI, IPV, sex, polycystic disease, etc., expanding the possibilities of modulating UF. Furthermore, our analysis of the behavior of UF when modifying each patient's IPV suggests a way to improve a personalized prescription: In addition to using IPV to optimize solute clearance avoiding discomfort, choking, hernias, leaks, reflux, etc., we can now better predict its effect on UF in each specific patient. This knowledge opens the possibility of modifying IPV together with dwell time to design schemes for diurnal or nocturnal dwell cycles that are optimized to each hemodynamic situation, making the most out of techniques such as advanced automated PD $(41,42)$. New studies in this field will expand the clinical possibilities and possibly provide new knowledge about peritoneal transport in PD.

This study confirms that, even with the intense osmotic strength of $2.27 \%$ glucose, UF can be significantly affected by factors so far considered marginal, primarily IPP and other factors associated with sex, yet to be identified. These factors are modulated by IPV, obesity, the presence of polycystosis and hernias. These variables could be taken into account, together with the osmotic gradient, in the diagnosis and management of UF failure.

Author's note: The results presented in this article have not been published previously in whole or part, except in abstract format. (XLVI Congreso Nacional de la Sociedad Española de Nefrología, Oviedo, 8-11 October 2016; LIII Reunión de la Sociedad Castellano Astur Leonesa de Nefrología SCALN, León, 21-22 October 2016; 54th European Renal Association - European Dialysis and Transplant Association ERA-EDTA Congress. Madrid, 3-6 june 2017; Meeting of Grupo Centro de Diálisis Peritoneal (GCDP), Madrid, 28 june 2017; XLVIII Congreso Nacional de la Sociedad Española de Nefrología / IX Congreso Iberoamericano de Nefrología, Madrid, 16-19 noviembre 2018; LV Reunión de la Sociedad Castellano Astur Leonesa de Nefrología. Palencia, 19-20 October 2018).

Acknowledgments: The authors thank Lucila Fernández-Arroyo, Ana Dorado-García, Isabel Casanova-Mateo and Berta Martín-Alcón for all the nursing work. 
Author contributions: V.P.D., S.S.B., L.S.G., E.H.G. and V.O.G. contributed to all aspects of the article. V.P.D. conceived and designed this study with principal inputs from S.S.B., L.S.G., E.H.G. and V.O.G., that also supervised the experiments and contributed to the acquisition and interpretation of data. V.P.D. and A.P.E. performed data analysis and interpretation with collaboration of A.S.P. Also V.P.D., A.S.P. and A.P.E. with important inputs o al co-authors performed previous presentations of data and conception of tables and figures. V.P.D and A.P.E. wrote the manuscript, which was critically reviewed and approved by all co-authors.

Declaration of conflicting interest: None declared.

Ethical Approval: Treatment protocol complied with the Declaration of Helsinki and was approved by the Ethics Committee of Clinical Investigation of Area de Salud Valladolid- Este (CEIC-VA-ESTE-HCUV) (PI 16 - 348 CINV 15 - 78) and the Research Committee of the Hospitals Clínico Universitario de Valladolid, Río Hortega de Valladolid and Complejo Asistencial Universitario de Palencia, Spain. Patients provided their written informed consent to participate and for the results to be published anonymously, before being treated.

Funding: A.P.-E. was funded by a Human Frontier Science Program fellowship (LT000537/2015), a Momentum Grant (CNRS) and a Fyssen Foundation Research grant.

\section{REFERENCES}

1. Teitelbaum I. Ultrafiltration failure in peritoneal dialysis: A pathophysiologic approach. Blood Purif. 2015;39(1-3):70-3.

2. Kim Y-L, Biesen W Van. Fluid Overload in Peritoneal Dialysis Patients. Semin Nephrol [Internet]. 2017;37(1):43-53. Available from: http://linkinghub.elsevier.com/retrieve/pii/S0270929516301012

3. Blake PG, Daugirdas JT. Physiology of peritoneal dialysis. In: Daugirdas JT, Blake PG, Ing TS, editors. Handbook of Dialysis Fifth Edition. Wolters Kluwer Health; 2015. p. 392-407.

4. Twardowski ZJ, Prowant BF, Nolph KD, Martinez AJ, Lampton LM. High volume, low frequency continuous ambulatory peritoneal dialysis. Kidney Int. 1983;23:64-70.

5. Twardowski ZJ, Khanna R, Nolph KD, Scalamogna A, Metzler MH, Schneider TW, et al. Intraabdominal pressures during natural activities in patients treated with continuous ambulatory peritoneal dialysisis. Nephron. 1986;44:129-35.

6. Imholz ALT, Koomen GCM, Struijk DG, Aiusz L, Krediet RT. Effect of an increased intraperitoneal pressure on fluid and solute transport during CAPD. 
Kidney Int. 1993;44(5):1078-85.

7. Durand PY, Chanliau J, Gamberoni J, Hestin D, Kessler M. Intraperitoneal Hydrostatic Pressure and Ultrafiltration Volume in CAPD. Adv Perit Dial. 1993;9:46-8.

8. Fischbach M, Terzic J, Laugel V, Escande B, Dangelser C, Helmstetter A. Measurement of hydrostatic intraperitoneal pressure: A useful tool for the improvement of dialysis dose prescription. Pediatr Nephrol. 2003;18(10):976-80.

9. Durand PY, Chanliau J, Gamberoni J, Hestin D, Kessler M. Intraperitoneal Pressure, Peritoneal Permeability and Volume of Ultrafiltration In CAPD. Adv Perit Dial. 1992;8:22-5.

10. Fischbach M, Desprez P, Donnars F, Geisert J. Hydrostatic Intraperitoneal Pressure in Children on Peritoneal Dialysis: Practical Implications. An 18 Month Clinical Experience. Adv Perit Dial [Internet]. 1994;10:294-6. Available from: http://www.ncbi.nlm.nih.gov/pubmed/7999848

11. Rusthoven E, Van Der Vlugt ME, Van Lingen - Van Bueren LJ, Van Schaijk TCJG, Willems HL, Monnens LAH, et al. Evaluation of intraperitoneal pressure and the effect of different osmotic agents on intraperitoneal pressure in children. Perit Dial Int [Internet]. 2005;25(4):352-6. Available from: www.PDIConnect.com

12. Fischbach M, Warady BA. Peritoneal dialysis prescription in children: Bedside principles for optimal practice. Pediatr Nephrol. 2009;24(9):1633-42.

13. Wang T, Heimburger O, Cheng HH, Waniewski J, Bergstrom J, Lindholm B. Effect of increased dialysate fill volume on peritoneal fluid and solute transport. Kidney Int. 1997;52(4):1068-76.

14. Flessner MF, Dedrick RL, Schultz JS. A distributed model of peritoneal-plasma transport: analysis of experimental data in the rat. Am J Physiol [Internet]. 1985 Mar;248(3 Pt 2):F413-24. Available from: http://www.ncbi.nlm.nih.gov/pubmed/3976900

15. Betancourt Castellanos L, Ponz Clemente E, Blasco Cabañas C, Marquina Parra $\mathrm{D}$, Bolós Contador M, Oliva JC, et al. Clinical relevance of intraperitoneal pressure in peritoneal dialysis patients. Perit Dial Int. 2017;37(5):562-7.

16. Pérez Díaz V, Sanz Ballesteros S, Hernández García E, Descalzo Casado E, Herguedas Callejo I, Ferrer Perales C. Intraperitoneal pressure in peritoneal dialysis. Nefrol (English Ed [Internet]. 2017 Nov;37(6):579-86. Available from: https://linkinghub.elsevier.com/retrieve/pii/S2013251417301864

17. Fukatsu A, Komatsu Y, Senou H, Miyai H, Tanaka Y, Oiwa T, et al. Clinical benefits and tolerability of increased fill volumes in Japanese peritoneal dialysis patients. Perit Dial Int. 2001;21(5):455-61.

18. Paniagua Sierra JR, De Jesús Ventura M, Rodríguez E, Sil J, Galindo T, Hurtado $\mathrm{ME}$, et al. Impact of fill volume on peritoneal clearances and cytokine appearance in peritoneal dialysis. Perit Dial Int. 2004;24:156-62.

19. Krediet RT, Boeschoten E, Struijk DG, Arisz L. Differences in the peritoneal transport of water, solutes and proteins between dialysis with two- and with threelitre exchanges. Nephrol Dial Transplant. 1988;2:198-204. 
20. Kuriyama S, Otsuka Y, Iida R, Matsumoto K, Hosoya T. Icodextrin with small and short dwell enhances ultrafiltration in peritoneal dialysis patients with severe overhydration [2]. Perit Dial Int. 2006;26(4):508-9.

21. Fischbach M, Terzic J, Dangelser C, Schneider P, Roger ML, Geisert J. Effect of posture on intraperitoneal pressure and peritoneal permeability in children. Pediatr Nephrol. 1998;12:311-4.

22. Perez-Diaz V, Perez-Escudero A, Sanz-Ballesteros S, Rodriguez Portela G, Valenciano-Martínez S, Palomo-Aparicio S, et al. A new method to increase ultrafiltration in peritoneal dialysis: Steady concentration peritoneal dialysis. Perit Dial Int. 2016;36(5):555-61.

23. Durand PY, Chanliau J, Gamberoni J, Hestin D, Kessler M. Routine measurement of hydrostatic intraperitoneal pressure. Adv Perit Dial. 1992;8:108-12.

24. Dejardin A, Robert A, Goffin E. Intraperitoneal pressure in PD patients: Relationship to intraperitoneal volume, body size and PD-related complications. Nephrol Dial Transplant. 2007;22(5):1437-44.

25. Al-Hwiesh A, Al-Mueilo S, Saeed I, Al-Muhanna FA. Intraperitoneal pressure and intra-abdominal pressure: Are they the same? Perit Dial Int. 2011;31(3):315-9.

26. Durand PY. Measurement of intraperitoneal pressure in PD patients. Perit Dial Int. 2005;25(4):333-7.

27. Ventura M-J, Amato D, Correa-Rotter R, Paniagua R. Relationship between fill volume, intraperitoneal pressure, body size, and subjetive discomfort perception in CAPD patients. Perit Dial Int. 2000;20(July 1999):188-93.

28. Outerelo M., Gouvela R, Teixeira e Costa F, Ramos A. Intraperitoneal pressure has a prognostic impact on peritoneal dialysis patients. Perit Dial Int. 2014;34(6):652-4.

29. Chien CC, Wang HY, Chien TW, Kan WC, Su S Bin, Lin CY. A reference equation for objectively adjusting dwell volume to obtain more ultrafiltration in daily practice of peritoneal dialysis. Ren Fail [Internet]. 2010 Mar 3;32(2):185-91. Available

from:

http://www.tandfonline.com/doi/full/10.3109/08860220903541127

30. Sanchez NC, Tenofsky PL, Dort JM, Shen LY, Helmer SD, Smith RS. What is normal intra-abdominal pressure? Am Surg. 2001;67(3):243-8.

31. Scanziani R, Dozio B, Baragetti I, Maroni S. Intraperitoneal hydrostatic pressure and flow characteristics of peritoneal catheters in automated peritoneal dialysis. Nephrol Dial Transplant. 2003;18:2391-8.

32. Del Peso G, Bajo-Rubio MA, Costero O, Hevia C, Gil F, Diaz C, et al. Risk factors for abdominal wall complications in peritoneal dialysis patients. Perit Dial Int [Internet]. 2003;23(3):249-54. Available from: http://ovidsp.ovid.com/ovidweb.cgi?T $=\mathrm{JS} \& \mathrm{PAGE}=$ reference $\& \mathrm{D}=\mathrm{emed} 8 \& \mathrm{NEW}$ $\mathrm{S}=\mathrm{N} \& \mathrm{AN}=37045661$

33. Khan S, Giuliani A, Crepaldi C, Ronco C, Rosner MH. Peritoneal dialysis for patients with autosomal dominant polycystic kidney disease. Perit Dial Int. 2017;37(4):384-8.

34. Smit M, Werner MJM, Lansink-Hartgring AO, Dieperink W, Zijlstra JG, van 
Meurs M. How central obesity influences intra-abdominal pressure: a prospective, observational study in cardiothoracic surgical patients. Ann Intensive Care [Internet]. 2016;6(1):99-108. Available from: http://www.annalsofintensivecare.com/\%0Ahttp://ovidsp.ovid.com/ovidweb.cgi? $\mathrm{T}=\mathrm{JS} \& \mathrm{CSC}=\mathrm{Y} \& \mathrm{NEWS}=\mathrm{N} \& \mathrm{PAGE}=$ fulltext $\& \mathrm{D}=$ emed1 $8 \mathrm{~b} \& \mathrm{AN}=612637314$

35. Durand PY, Chanliau J, Gamberoni J, Hestin D, Kessler M. APD: Clinical measurement of the maximal acceptable intraperitoneal volume. Adv Perit Dial. 1994;10:63-7.

36. Durand PY, Chanliau J, Gamberoni J, Hestin D, Kessler M. Measurement of hydrostatic intraperitoneal pressure: a necessary routine test in peritoneal dialysis. Perit Dial Int. 1996;16(Suppl 1):S84-7.

37. Goldschmidt ZH, Pote HH, Katz MA, Shear L. Effect of dialysate volume on peritoneal dialysis kinetics. Kidney Int [Internet]. 1974;5(3):240-5. Available from: http://dx.doi.org/10.1038/ki.1974.29

38. Durand PY. Optimization of fill volumes in automated peritoneal dialysis. Perit Dial Int. 2000;20(6):601-2.

39. Palmer BF, Clegg DJ. The sexual dimorphism of obesity. Mol Cell Endocrinol [Internet]. $2015 \quad$ Feb;402:113-9. Available from: https://linkinghub.elsevier.com/retrieve/pii/S0303720714004213

40. Imholz AL, Koomen GC, Voorn WJ, Struijk DG, Arisz L, Krediet RT. Day-today variability of fluid and solute transport in upright and recumbent positions during CAPD. Nephrol Dial Transplant [Internet]. 1998 Jan 1;13(1):146-53.

Available from: https://academic.oup.com/ndt/articlelookup/doi/10.1093/ndt/13.1.146

41. Fischbach M, Issad B, Dubois V, Taamma R. The beneficial influence on the effectiveness of Automated Peritoneal Dialysis of varying the dwell time (short/long) and fill volume (small/large): A rendomized controlled trial. Perit Dial Int. 2011;31(4):450-8.

42. Öberg CM, Rippe B. Is adapted APD theoretically more efficient than conventional APD? Perit Dial Int [Internet]. 2017 Feb 4 [cited 2016 Nov 17];37(2):212-7. Available

from:

http://www.ncbi.nlm.nih.gov/pubmed/26847586 
Table 1. Characteristics of patients.

\begin{tabular}{|c|c|c|c|c|c|c|c|}
\hline & \multicolumn{2}{|c|}{ All patients $(n=41)$} & \multicolumn{2}{|c|}{ Men $(n=30)$} & \multirow[b]{2}{*}{$\mathbf{p}^{+}$} & \multicolumn{2}{|c|}{ Women $(n=11)$} \\
\hline & mean $\pm S D$ & Range & mean $\pm S D$ & range & & mean $\pm S D$ & range \\
\hline Age (years) & $59.2 \pm 12.0$ & $37.0-81.0$ & $60.2 \pm 12.1$ & $37.0-81.0$ & 0.408 & $56.6 \pm 12.1$ & $39.0-78.0$ \\
\hline Weight (kg) & $75.0 \pm 14.3$ & $48.1-112.0$ & $79.1 \pm 12.6$ & $62.4-112.0$ & 0.001 & $63.7 \pm 13.0$ & $48.1-94.3$ \\
\hline BS (m2) & $1.85 \pm 0.20$ & $1.43-2.34$ & $1.92 \pm 0.17$ & $1.68-2.34$ & 0.0002 & $1.67 \pm 0.17$ & $1.43-2.03$ \\
\hline Height (m) & $1.66 \pm 0.08$ & $1.43-1.81$ & $1.69 \pm 0.07$ & $1.47-1.81$ & 0.0004 & $1.59 \pm 0.08$ & $1.43-1.72$ \\
\hline BMI (kg/m2) & $27.10 \pm 4.53$ & $19.84-37.77$ & $27.76 \pm 4.07$ & $20.79-36.36$ & 0.130 & $25.33 \pm 5.41$ & $19.84-37.77$ \\
\hline Time in PD (months) & $24.7 \pm 27.5$ & $2.3-123.8$ & $28.2 \pm 30.8$ & $2.6-123.8$ & 0.182 & $15.2 \pm 11.8$ & $2.3-42.2$ \\
\hline Comorbidity, Charlson Index & $4.5 \pm 1.9$ & $2.0-9.6$ & $4.8 \pm 1.9$ & $2.0-9.6$ & 0.108 & $3.7 \pm 1.8$ & $2.0-7.0$ \\
\hline CRP (mg/L) & $4.5 \pm 6.3$ & $1.0-29.0$ & $5.4 \pm 7.1$ & $1.0-29.0$ & 0.113 & $1.9 \pm 1.2$ & $1.0-4.0$ \\
\hline Final Glucose $2.5 \mathrm{~L}(\mathrm{mg} / \mathrm{dL})$ & $1079 \pm 190$ & $690-1486$ & $1089 \pm 188$ & $690-1486$ & 0.561 & $1048 \pm 200$ & $741-1403$ \\
\hline Final Glucose $1.5 \mathrm{~L}(\mathrm{mg} / \mathrm{dL})$ & $967 \pm 176$ & $532-1303$ & $968 \pm 188$ & $532-1303$ & 0.943 & $963 \pm 142$ & $780-1268$ \\
\hline Final Osmolarity $2.5 \mathrm{~L}$ (mOsm/L) & $333 \pm 7$ & $320-347$ & $334 \pm 8$ & $320-347$ & 0.325 & $331 \pm 6$ & $320-338$ \\
\hline Final Osmolarity $1.5 \mathrm{~L}$ (mOsm/L) & $326 \pm 7$ & $315-340$ & $326 \pm 7$ & 315 - 340 & 0.499 & $324 \pm 6$ & 315 - 334 \\
\hline D/P Urea PET 3.86\% * & $0.91 \pm 0.05$ & $0.79-1.03$ & $0.91 \pm 0.05$ & $0.79-1.01$ & 0.479 & $0.92 \pm 0.05$ & $0.85-1.03$ \\
\hline D/P Creatinine PET $3.86 \%$ * & $0.74 \pm 0.07$ & $0.52-0.86$ & $0.73 \pm 0.08$ & $0.52-0.86$ & 0.208 & $0.77 \pm 0.05$ & $0.71-0.84$ \\
\hline D/D0 Glucose PET 3.86\% * & $0.28 \pm 0.07$ & $0.17-0.42$ & $0.29 \pm 0.07$ & $0.19-0.42$ & 0.397 & $0.27 \pm 0.07$ & $0.17-0.36$ \\
\hline UF PET $3.86 \%(\mathrm{~mL}) *$ & $643 \pm 228$ & $100-1070$ & $668 \pm 230$ & $100-1070$ & 0.320 & $573 \pm 221$ & $356-1020$ \\
\hline IPP with 2.5L (cmH2O) & $14.0 \pm 4.4$ & $4.5-24.0$ & $14.1 \pm 4.7$ & $4.5-24.0$ & 0.778 & $13.6 \pm 3.8$ & $10.0-23.5$ \\
\hline IPP with 1.5L (cmH2O) & $11.2 \pm 4.3$ & $0.5-20.5$ & $11.6 \pm 4.1$ & $1.5-20.5$ & 0.434 & $10.4 \pm 4.9$ & $0.5-20.5$ \\
\hline Void IPP (cmH2O) & $8.6 \pm 4.2$ & $0.0-18.0$ & $9.1 \pm 4.2$ & $0.0-18.0$ & 0.183 & $7.1 \pm 4.0$ & $1.5-16.5$ \\
\hline$\Delta$ PIP with IPV (cmH2O/L) & $2.12 \pm 0.86$ & $-0.07-4.92$ & $1.90 \pm 0.76$ & $-0.07-3.38$ & 0.006 & $2.72 \pm 0.87$ & $1.67-4.92$ \\
\hline UF 2.5L (mL) & $128 \pm 207$ & $-400-550$ & $91 \pm 215$ & $-400-550$ & 0.059 & $229 \pm 152$ & $0-470$ \\
\hline UF 1.5L (mL) & $195 \pm 145$ & $-49-550$ & $218 \pm 146$ & $-26-550$ & 0.097 & $133 \pm 128$ & $-49-350$ \\
\hline Variation UF from 1.5 to $2.5 \mathrm{~L}(\mathrm{~mL})$ & $68 \pm 252$ & $-250-800$ & $127 \pm 264$ & $-200-800$ & 0.010 & $-95 \pm 106$ & $-250-100$ \\
\hline
\end{tabular}

* PET parameters were available only for 31 patients ( 23 men, 8 women)

$+p$-value for the comparison between men and women (Student's t-test)

Table 1. Characteristics of patients. $B S=B$ ody surface area (Mosteller). BMI=Body mass Index. $C R P=$ ultrasensitive $C$-reactive protein. UF=Ultrafiltration. IPP=Intraperitoneal pressure. IPV=Intraperitoneal volume. $\triangle \mathrm{IPP}$ with IPV=Rate of increase of IPP with IPV. 
Table 2.- Comparison of final composition, pressure and ultrafiltration of both exchanges. Differences between men and women.

\begin{tabular}{|c|c|c|c|c|c|c|c|c|c|c|c|c|}
\hline & \multicolumn{3}{|c|}{ Final Glucose (mg/dt) } & \multicolumn{3}{|c|}{ Final Osmolarity (mOsm/L) } & \multicolumn{3}{|c|}{ IPP $\left(\mathrm{cmH}_{2} \mathrm{O}\right)$} & \multicolumn{3}{|c|}{ UF (mL) } \\
\hline & $2.5 \mathrm{~L}$ & $1.5 \mathrm{~L}$ & $\mathrm{p}$ & $2.5 \mathrm{~L}$ & $1.5 \mathrm{~L}$ & $\mathrm{p}$ & $2.5 \mathrm{~L}$ & $1.5 \mathrm{~L}$ & $\mathrm{p}$ & $2.5 \mathrm{~L}$ & $1.5 \mathrm{~L}$ & $\mathrm{p}$ \\
\hline All patients & $1.079 \pm 190$ & $967 \pm 176$ & $<10^{-5}$ & $333 \pm 7$ & $326 \pm 7$ & $<10^{-5}$ & $14.0 \pm 4.4$ & $11.2 \pm 4.3$ & $<10^{-5}$ & $128 \pm 207$ & $195 \pm 145$ & 0.09 \\
\hline Men & $1.089 \pm 188$ & $968 \pm 188$ & $<10^{-5}$ & $334 \pm 8$ & $326 \pm 7$ & $<10^{-5}$ & $14.1 \pm 4.7$ & $11.6 \pm 4.1$ & $<10^{-5}$ & $91 \pm 215$ & $218 \pm 146$ & 0.01 \\
\hline$p$ & 0.6 & 0.9 & & 0.3 & 0.5 & & 0.8 & 0.4 & & 0.06 & 0.1 & \\
\hline Women & $1.048 \pm 200$ & $963 \pm 142$ & 0.006 & $331 \pm 6$ & $324 \pm 6$ & $<10^{-5}$ & $13.6 \pm 3.8$ & $10.4 \pm 4.9$ & 0,0006 & $229 \pm 152$ & $133 \pm 128$ & 0.01 \\
\hline
\end{tabular}

Table 2. Comparison between exchanges. Values (mean $\pm \mathrm{sd}$ ) for effluent glucose, effluent osmolarity, intraperitoneal pressure and ultrafiltration for the two exchanges (1.5 L and $2.5 \mathrm{~L}$ ). Numbers on grey background are $p$-values for the comparison between each pair of adjacent cells. Comparisons between the two exchanges were done using paired Student's $t$-tests. Comparisons between men and women were done using unpaired Student's $t$ tests. 


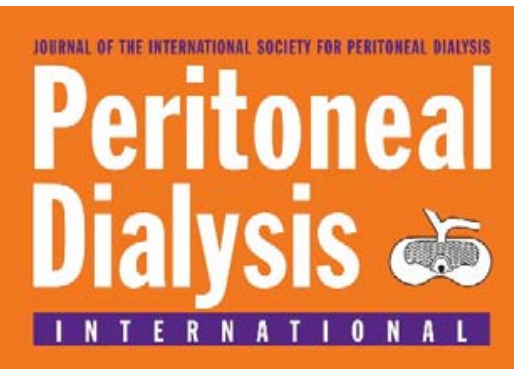

Supplemental Materials for

\section{Clinical relevance of marginal factors on ultrafiltration in peritoneal dialysis}

Vicente Pérez-Díaz (MD, PhD), Alfonso Pérez-Escudero (PhD), Sandra Sanz-Ballesteros (MD, PhD), Luisa Sánchez-García (MD), Esther Hernández-García (MD), Victoria Oviedo-Gómez (MD), Alicia Sobrino-Pérez (MD)

\section{Supplemental Material File Listing}

Table 0-S: Characteristic of patients. Median and IQR.

Table 1-S: Characteristic of patients, including men, women and women with and without previous pregnancies.

Table 2-S: Comparison of final composition, pressure and ultrafiltration of both exchanges. Differences between men, women and women with and without previous pregnancies.

Figure 2C-S: Same as figure 2.C. Difference between UF in the $2.5 \mathrm{~L}$ and $1.5 \mathrm{~L}$ exchange, vs IPP, signaling women with and without previous pregnancies.

Figure 3-S: Same as figure 3. Clinical impact, but differentiating women with and without previous pregnancies

Figure 4-S: Ultrafiltration with $1.5 \mathrm{~L}$ and $2.5 \mathrm{~L}$ in men and women, and in women with and without previous pregnancies.

\section{< Correspondence and requests for materials should be addressed to:}

Vicente Pérez-Díaz. Servicio de Nefrología. Hospital Clínico Universitario de Valladolid. Avenida Ramón y Cajal 3. 47003 Valladolid. Spain. Phone: +34 619591 281. Fax: +34 983257 511. E-mail: vperez5651@gmail.com.

$<$ Insert Corresponding Author Information here>> 


\begin{tabular}{|c|c|c|c|c|c|c|}
\hline & All pa & tients $(n=41)$ & Men & $(n=30)$ & Wom & $(n=11)$ \\
\hline & median & IQ1 - IQ3 & median & IQ1 - IQ3 & median & IQ1 - IQ3 \\
\hline Age (years) & 60.0 & $(49.0-68.0)$ & 60.0 & $(50.0-68.5)$ & 50.0 & $(48.0-69.0)$ \\
\hline Weight (kg) & 71.2 & $(64.7-84.8)$ & 76.1 & $(69.9-89.4)$ & 59.1 & $(53.7-70.5)$ \\
\hline $\mathrm{BS}\left(\mathrm{m}^{2}\right)$ & 1.83 & $(1.69-2.00)$ & 1.87 & $(1.79-2.09)$ & 1.64 & $(1.54-1.79)$ \\
\hline Height (m) & 1.67 & $(1.60-1.72)$ & 1.69 & $(1.66-1.74)$ & 1.59 & $(1.55-1.66)$ \\
\hline BMI $\left(\mathrm{kg} / \mathrm{m}^{2}\right)$ & 26.02 & $(24.33-29.86)$ & 26.64 & $(25.13-31.50)$ & 24.60 & $(20.55-27.89)$ \\
\hline Time in PD (months) & 12.4 & $(7.7-37.8)$ & 13.9 & $(7.9-42.8)$ & 12.4 & $(5.6-20.6)$ \\
\hline Comorbidity, Charlson Index & 4.0 & $(3.0-6.1)$ & 4.8 & $(3.0-6.2)$ & 3.1 & $(2.0-4.0)$ \\
\hline $\mathrm{CRP}(\mathrm{mg} / \mathrm{L})$ & 2.0 & $(1.0-5.0)$ & 3.1 & $(1.0-6.0)$ & 1.0 & $(1.0-3.0)$ \\
\hline Final Glucose $2.5 \mathrm{~L}(\mathrm{mg} / \mathrm{dL})$ & 1084 & (953 - 1 195) & 1083 & (954 - 1220$)$ & 1084 & $(846-1$ 156) \\
\hline Final Glucose $1.5 \mathrm{~L}(\mathrm{mg} / \mathrm{dL})$ & 962 & $(830-1110)$ & 964 & $(823-1132)$ & 957 & $(852-1027)$ \\
\hline Final Osmolarity $2.5 \mathrm{~L}(\mathrm{mOsm} / \mathrm{L})$ & 334 & $(328-339)$ & 334 & $(328-341)$ & 334 & $(327-336)$ \\
\hline Final Osmolarity $1.5 \mathrm{~L}(\mathrm{mOsm} / \mathrm{L})$ & 324 & $(321-332)$ & 324 & $(321-332)$ & 325 & $(319-329)$ \\
\hline D/P Urea PET 3.86\%* & 0.91 & $(0.88-0.93)$ & 0.90 & $(0.88-0.93)$ & 0.92 & $(0.89-0.94)$ \\
\hline D/P Creatinine PET 3.86\% * & 0.74 & $(0.70-0.78)$ & 0.74 & $(0.68-0.78)$ & 0.77 & $(0.72-0.81)$ \\
\hline D/DO Glucose PET 3.86\% * & 0.27 & $(0.23-0.33)$ & 0.29 & $(0.24-0.33)$ & 0.27 & $(0.19-0.35)$ \\
\hline UF PET $3.86 \%(\mathrm{~mL}) *$ & 600 & $(500-800)$ & 650 & $(540-834)$ & 519 & $(390-713)$ \\
\hline IPP with $2.5 \mathrm{~L}\left(\mathrm{cmH}_{2} \mathrm{O}\right)$ & 13.5 & $(11.3-16.0)$ & 13.5 & $(11.5-16.3)$ & 14.0 & $(11.0-14.5)$ \\
\hline IPP with $1.5 \mathrm{~L}\left(\mathrm{cmH}_{2} \mathrm{O}\right)$ & 11.0 & $(8.8-14.3)$ & 10.8 & $(9.4-15.0)$ & 11.0 & $(8.0-12.5)$ \\
\hline Void IPP $\left(\mathrm{cmH}_{2} \mathrm{O}\right)$ & 9.0 & $(6.0-11.3)$ & 9.0 & $(6.4-12.5)$ & 6.0 & $(5.0-9.5)$ \\
\hline$\Delta \mathrm{IPP}$ with IPV $\left(\mathrm{cmH}_{2} \mathrm{O} / \mathrm{L}\right)$ & 2.06 & $(1.69-2.57)$ & 1.99 & $(1.51-2.40)$ & 2.52 & $(2.27-2.99)$ \\
\hline UF $2.5 \mathrm{~L}(\mathrm{~mL})$ & 150 & $(0-265)$ & 38 & $(-50-224)$ & 250 & $(100-344)$ \\
\hline UF 1.5L (mL) & 190 & $(89-290)$ & 225 & $(100-300)$ & 150 & $(31-235)$ \\
\hline Variation UF from 1.5 to $2.5 \mathrm{~L}(\mathrm{~mL})$ & -16 & $(-103-200)$ & 50 & $(-90-250)$ & -109 & $(-190--25)$ \\
\hline
\end{tabular}

* PET parameters were available only for 31 patients ( 23 men, 8 women)

Table 0-S.- Characteristics of patients. Median and interquartile range of the variables collected, useful for a better perception of the variables that have non-normal distribution, such as time in $P D, C R P$, etc.

$\mathrm{BS}=\mathrm{Body}$ surface area (Mosteller). $\mathrm{BMI}=\mathrm{Body}$ mass Index. $\mathrm{CRP}=$ ultrasensitive C-reactive protein. $U F=U l$ trafiltration. IPP=Intraperitoneal pressure. IPV=Intraperitoneal volume. $\triangle I P P$ with IPV=Rate of increase of IPP with IPV. 
Table 1S. Characteristics of patients. By sex and considering women with and without previous pregnancies

\begin{tabular}{|c|c|c|c|c|c|c|c|c|c|c|c|c|c|c|}
\hline \multirow[b]{4}{*}{ Age (vears) } & \multicolumn{7}{|c|}{ All patients and differences between men and women (mean \pm SD and range) } & \multicolumn{7}{|c|}{ Women with / without previous pregnancies ( $t$ Test between them and with men) } \\
\hline & \multicolumn{2}{|c|}{ All patients $(n=41)$} & \multicolumn{2}{|c|}{$\operatorname{Men}(n=30)$} & \multirow[b]{2}{*}{$p$ (t Test) } & \multicolumn{2}{|c|}{ Women ( $n=11)$} & \multirow{2}{*}{$\begin{array}{l}\text { P vs Men } \\
\text { p (t Test) }\end{array}$} & \multicolumn{2}{|c|}{ W Pregnancies $(n=6)$} & \multirow{2}{*}{$\begin{array}{l}P \text { vs NoP } \\
p \text { (t Test) }\end{array}$} & \multirow{2}{*}{$\begin{array}{l}\text { N vs Men } \\
\text { p (t Test) }\end{array}$} & \multicolumn{2}{|c|}{ W No Pregnancies $(n=5)$} \\
\hline & mean \pm SD & range & mean \pm SD & range & & mean \pm SD & range & & mean \pm SD & range & & & mean \pm SD & range \\
\hline & $59.2 \pm 12.0$ & $37.0-81.0$ & $60.2 \pm 12.1$ & $37.0-81.0$ & 0.408 & $56.6 \pm 12.1$ & $39.0-78.0$ & 0.629 & $62.8 \pm 12.1$ & $48.0-78.0$ & 0.057 & 0.059 & $49.2 \pm 7.5$ & $39.0-60.0$ \\
\hline Weight (kg) & $75.0 \pm 14.3$ & $48.1-112.0$ & $79.1 \pm 12.6$ & $62.4-112.0$ & 0.001 & $63.7 \pm 13.0$ & $48.1-94.3$ & 0.011 & $64.6 \pm 8.4$ & $53.7-74.4$ & 0.825 & 0.017 & $62.7 \pm 18.2$ & $48.1-94.3$ \\
\hline BS (m2) & $1.85 \pm 0.20$ & $1.43-2.34$ & $1.92 \pm 0.17$ & $1.68-2.34$ & 0.000 & $1.67 \pm 0.17$ & $1.43-2.03$ & 0.004 & $1.70 \pm 0.10$ & $1.54-1.80$ & 0.612 & 0.003 & $1.64 \pm 0.24$ & $1.43-2.03$ \\
\hline Height (m) & $1.66 \pm 0.08$ & $1.43-1.81$ & $1.69 \pm 0.07$ & $1.47-1.81$ & 0.000 & $1.59 \pm 0.08$ & $1.43-1.72$ & 0.014 & $1.61 \pm 0.05$ & $1.55-1.67$ & 0.352 & 0.002 & $1.56 \pm 0.10$ & $1.43-1.72$ \\
\hline BMI (kg/m2) & $27.10 \pm 4.53$ & $19.84-37.77$ & $27.76 \pm 4.07$ & $20.79-36.36$ & 0.130 & $25.33 \pm 5.41$ & $19.84-37.77$ & 0.140 & $25.01 \pm 4.03$ & $20.55-30.97$ & 0.846 & 0.360 & $25.70 \pm 7.26$ & $19.84-37.77$ \\
\hline Time in PD (months) & $24.7 \pm 27.5$ & $2.3-123.8$ & $28.2 \pm 30.8$ & $2.6-123.8$ & 0.182 & $15.2 \pm 11.8$ & $2.3-42.2$ & 0.436 & $18.0 \pm 14.5$ & $4.7-42.2$ & 0.410 & 0.249 & $11.8 \pm 7.6$ & $2.3-20.6$ \\
\hline Comorbidity, Charlson Index & $4.5 \pm 1.9$ & $2.0-9.6$ & $4.8 \pm 1.9$ & $2.0-9.6$ & 0.108 & $3.7 \pm 1.8$ & $2.0-7.0$ & 0.844 & $4.6 \pm 1.8$ & $3.0-7.0$ & 0.048 & 0.018 & $2.6 \pm 0.9$ & $2.0-4.0$ \\
\hline Final Glucose $2.5 \mathrm{~L}(\mathrm{mg} / \mathrm{dL})$ & $1079 \pm 190$ & $690-1486$ & $1089 \pm 188$ & $690-1486$ & 0.561 & $1048 \pm 200$ & $741-1403$ & 0.646 & $1048 \pm 248$ & $741-1403$ & 0.999 & 0.679 & $1048 \pm 134$ & $864-1147$ \\
\hline Final Glucose $1.5 \mathrm{~L}(\mathrm{mg} / \mathrm{dL})$ & $967 \pm 176$ & $532-1303$ & $968 \pm 188$ & $532-1303$ & 0.943 & $963 \pm 142$ & $780-1268$ & 0.863 & $984 \pm 205$ & $780-1268$ & 0.672 & 0.768 & $942 \pm 49$ & $873-1004$ \\
\hline Final Osmolarity 2. & $3 \pm 7$ & $320-347$ & $334 \pm 8$ & $320-347$ & 0.325 & $331 \pm 6$ & $320-338$ & 0.910 & $334 \pm 3$ & $330-338$ & 0.084 & 113 & $326 \pm 9$ & $320-336$ \\
\hline Final Osmolarity $1.5 \mathrm{~L}(\mathrm{mOsm} / \mathrm{L})$ & $326 \pm 7$ & $315-340$ & $326 \pm 7$ & $315-340$ & 0.499 & $324 \pm 6$ & $315-334$ & 0.926 & $326 \pm 3$ & $323-330$ & 0.468 & 0.355 & $323 \pm 9$ & $315-334$ \\
\hline D/P Urea PET 3.86\%* & $0.91 \pm 0.05$ & $0.79-1.03$ & $0.91 \pm 0.05$ & $0.79-1.01$ & 0.479 & $0.92 \pm 0.05$ & $0.85-1.03$ & 0.470 & $0.92 \pm 0.07$ & $0.85-1.03$ & 0.804 & 790 & $0.91 \pm 0.03$ & $0.88-0.94$ \\
\hline D/P Creatinine PET $3.86 \% *$ & $0.74 \pm 0.07$ & $0.52-0.86$ & $0.73 \pm 0.08$ & $0.52-0.86$ & 0.208 & $0.77 \pm 0.05$ & $0.71-0.84$ & 0.105 & $0.79 \pm 0.04$ & $0.73-0.84$ & 0.056 & 0.988 & $0.73 \pm 0.02$ & $0.71-0.75$ \\
\hline D/D0 Glucose PET 3.86\%* & $0.28 \pm 0.07$ & $0.17-0.42$ & $0.29 \pm 0.07$ & $0.19-0.42$ & 0.397 & $0.27 \pm 0.07$ & $0.17-0.36$ & 0.074 & $0.23 \pm 0.06$ & $0.17-0.30$ & 0.059 & 0.388 & $0.33 \pm 0.06$ & $0.26-0.36$ \\
\hline UF PET $3.86 \%(\mathrm{~mL}) *$ & $643 \pm 228$ & $100-1070$ & $668 \pm 230$ & $100-1070$ & 0.320 & $573 \pm 221$ & & 0.351 & $557 \pm 271$ & & 0.812 & 0.628 & $600 \pm 150$ & $450-750$ \\
\hline IPP with $2.5 \mathrm{~L}(\mathrm{cmH} 2 \mathrm{O})$ & $14.0 \pm 4.4$ & $4.5-24.0$ & $14.1 \pm 4.7$ & $4.5-24.0$ & 0.778 & $13.6 \pm 3.8$ & $10.0-23.5$ & 0.673 & $13.3 \pm 1.8$ & $11.0-15.0$ & 0.729 & 0.994 & $14.1 \pm 5.5$ & $10.0-23.5$ \\
\hline IPP with $1.5 \mathrm{~L}(\mathrm{cmH} 2 \mathrm{O})$ & $11.2 \pm 4.3$ & $0.5-20.5$ & $11.6 \pm 4.1$ & $1.5-20.5$ & 0.434 & $10.4 \pm 4.9$ & $0.5-20.5$ & 578 & $10.6 \pm 2.5$ & $6.5-12.5$ & 0.880 & 513 & $10.1 \pm 7.2$ & $0.5-20.5$ \\
\hline Void IPP (cmH2O) & $8.6 \pm 4.2$ & $0.0-18.0$ & $9.1 \pm 4.2$ & $0.0-18.0$ & 0.183 & $7.1 \pm 4.0$ & $1.5-16.5$ & 0.304 & $7.3 \pm 2.6$ & $4.0-10.0$ & 0.924 & 0.326 & $7.0 \pm 5.6$ & $1.5-16.5$ \\
\hline UF $2.5 \mathrm{~L}(\mathrm{~mL})$ & $128 \pm 207$ & $-400-550$ & $91 \pm 215$ & $-400-550$ & 0.059 & $229 \pm 152$ & $0-470$ & 0.447 & $163 \pm 162$ & $0-400$ & 0.117 & 0.035 & $308 \pm 101$ & $225-470$ \\
\hline UF $1.5 \mathrm{~L}(\mathrm{~mL})$ & $195 \pm 145$ & $-49-550$ & $218 \pm 146$ & $-26-550$ & 0.097 & $133 \pm 128$ & $-49-350$ & 0.007 & $42 \pm 77$ & $-49-150$ & 0.002 & 0.715 & $243 \pm 76$ & $150-350$ \\
\hline Variation UF from 1.5 to $2.5 \mathrm{~L}(\mathrm{~mL})$ & $68 \pm 252$ & $-250-800$ & $127 \pm 264$ & $-200-800$ & 0.010 & $-95 \pm 106$ & $-250-100$ & 0.032 & $-120 \pm 106$ & $-250-41$ & 0.416 & 0.122 & $-65 \pm 109$ & $-190-100$ \\
\hline
\end{tabular}

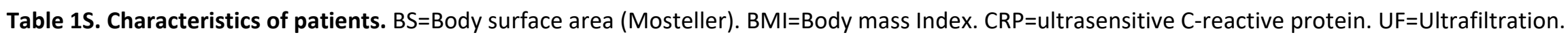
$I P P=$ Intraperitoneal pressure. IPV=Intraperitoneal volume. $\triangle I P P$ with IPV=Rate of increase of IPP with IPV. W=Women.

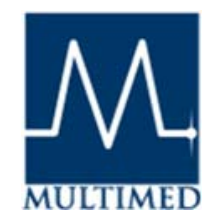


Table 2S. Comparison of composition of efluent, intraperitoneal pressure and ultrafiltration of both exchanges. Differences between men and all women and women with $(W+P)$ or without ( $W$ no $P$ ) previous pregnancies.

\begin{tabular}{|c|c|c|c|c|c|c|c|c|c|c|c|c|}
\hline \multicolumn{13}{|c|}{ Differences between both exchanges } \\
\hline & \multicolumn{3}{|c|}{ Glucose $(\mathrm{mg} / \mathrm{dL})$} & \multicolumn{3}{|c|}{ Osmolarity (mOsm/L) } & \multicolumn{3}{|c|}{ IPP $\left(\mathrm{cmH}_{2} \mathrm{O}\right)$} & \multicolumn{3}{|c|}{ UF (mL) } \\
\hline & $2.5 \mathrm{~L}$ & p & $1.5 \mathrm{~L}$ & $2.5 \mathrm{~L}$ & $\mathbf{p}$ & $1.5 \mathrm{~L}$ & $2.5 \mathrm{~L}$ & p & $1.5 \mathrm{~L}$ & $2.5 \mathrm{~L}$ & $\mathbf{p}$ & $1.5 \mathrm{~L}$ \\
\hline All & $1079 \pm 190$ & 0.0000 & $967 \pm 176$ & $333 \pm 7$ & 0.0000 & $326 \pm 7$ & $14.0 \pm 4.4$ & 0.0000 & $11.2 \pm 4.3$ & $128 \pm 207$ & 0.0935 & $195 \pm 145$ \\
\hline \multirow[t]{2}{*}{ Men } & $1089 \pm 188$ & 0.0000 & $968 \pm 188$ & $334 \pm 8$ & 0.0000 & $326 \pm 7$ & $14.1 \pm 4.7$ & 0.0000 & $11.6 \pm 4.1$ & $91 \pm 215$ & 0.0133 & $218 \pm 146$ \\
\hline & p $\quad 0.561$ & & 0.943 & 0.325 & & 0.499 & 0.778 & & 0.434 & 0.059 & & 0.097 \\
\hline Women & $1048 \pm 200$ & 0.0060 & $963 \pm 142$ & $331 \pm 6$ & 0.0000 & $324 \pm 6$ & $13.6 \pm 3.8$ & 0.0006 & $10.4 \pm 4.9$ & $229 \pm 152$ & 0.0140 & $133 \pm 128$ \\
\hline \multirow[t]{2}{*}{$\mathbf{W}+\mathbf{P}$} & $1048 \pm 248$ & 0.0060 & $984 \pm 205$ & $334 \pm 3$ & 0.0000 & $326 \pm 3$ & $13.3 \pm 1.8$ & 0.0006 & $10.6 \pm 2.5$ & $163 \pm 162$ & 0.0140 & $42 \pm 277$ \\
\hline & p $\quad 0.999$ & & 0.672 & 0.084 & & 0.468 & 0.729 & & 0.880 & 0.117 & & 0.002 \\
\hline W no P & $1048 \pm 134$ & 0.0060 & $942 \pm 49$ & $326 \pm 9$ & 0.0000 & $323 \pm 9$ & $14.1 \pm 5.5$ & 0.0006 & $10.1 \pm 7.2$ & $308 \pm 101$ & 0.0140 & $243 \pm 76$ \\
\hline p (+) vs me & en $\quad 0.646$ & & 0.863 & 0.910 & & 0.926 & 0.673 & & 0.578 & 0.447 & & 0.007 \\
\hline p (no) vs me & 0.679 & & 0.768 & 0.113 & & 0.355 & 0.994 & & 0.513 & 0.035 & & 0.715 \\
\hline
\end{tabular}

Table 2S. Comparison between exchanges. Values (mean $\pm \mathrm{sd}$ ) for effluent glucose, effluent osmolarity, intraperitoneal pressure and ultrafiltration for the two exchanges $(1.5 \mathrm{~L}$ and $2.5 \mathrm{~L}$ ). $p$-values for the comparison between each pair of adjacent cells. The last two lines, comparison between men and women with and without previous pregnancies. Comparisons between the two exchanges were done using paired Student's $t$-tests. Comparisons between men and women were done using unpaired Student's $t$-tests. 


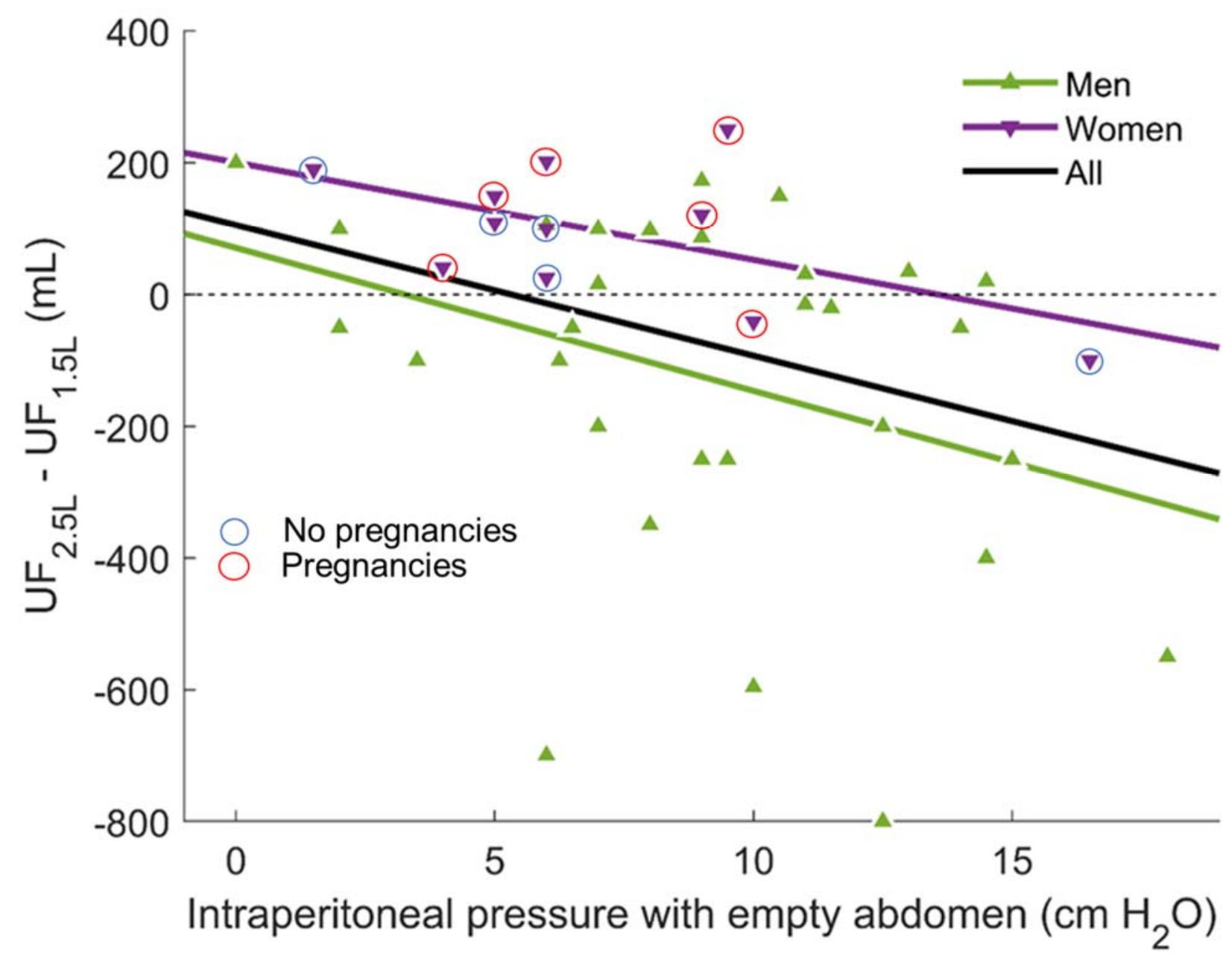

Figure 2C-S Same as figure 2C. The difference between UF in the $2.5 \mathrm{~L}$ and $1.5 \mathrm{~L}$ exchanges, vs IPP, show that women (with or without previous pregnancies) and patients with low IPP tend to have more UF with low intraperitoneal volume. Lines of best fit for men and women have slopes not different $(p=0.7)$ with a significant upwards shift for women $(p=0.022)$. 


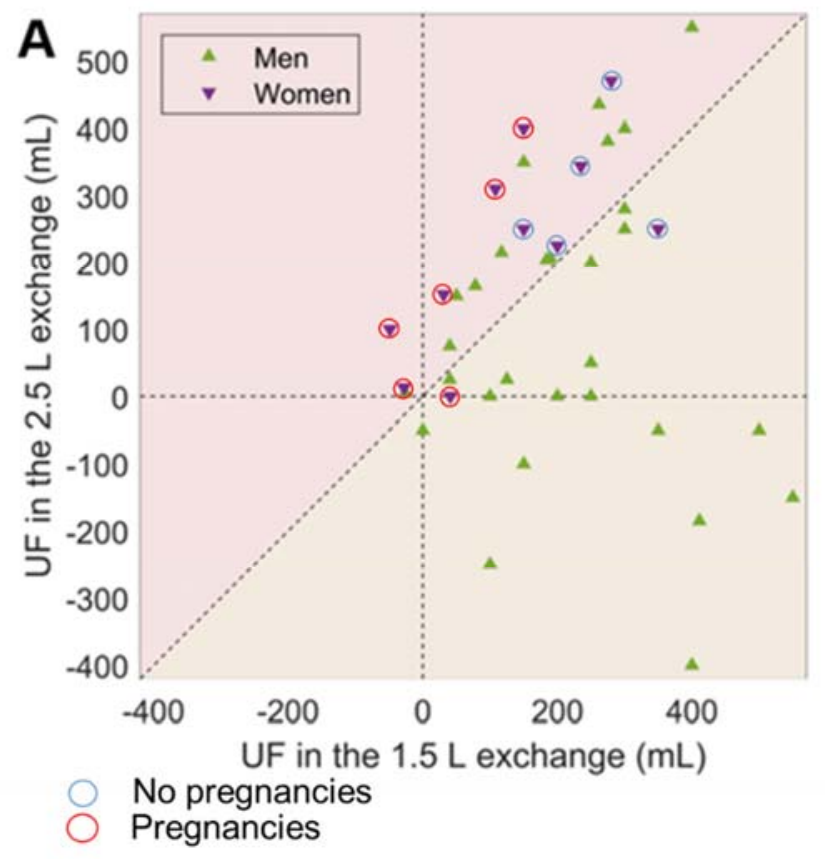

\begin{tabular}{l|ccc} 
B & $\begin{array}{c}\text { Patients that } \\
\text { increase } \\
\text { UF with IPV } \\
(n=21)\end{array}$ & $\begin{array}{c}\text { Patients that } \\
\text { decrease } \\
\text { UF with IPV } \\
(n=20)\end{array}$ & $p$ \\
\hline Glucose 2.5L (mg/dL) & $1101 \pm 128$ & $1057 \pm 159$ & 0.5 \\
Glucose 1.5L (mg/dL) & $1012 \pm 196$ & $921 \pm 143$ & 0.1 \\
Osmolarity 2.5L (mOs/L) & $331 \pm 7$ & $335 \pm 7$ & 0.1 \\
Osmolarity 1.5L (mOs/L) & $325 \pm 8$ & $326 \pm 6$ & 0.6 \\
\hline D/P creatinine & $0.71 \pm 0.09$ & $0.76 \pm 0.05$ & 0.07 \\
D/P urea & $0.90 \pm 0.05$ & $0.92 \pm 0.04$ & 0.1 \\
D/D0 glucose & $0.29 \pm 0.08$ & $0.28 \pm 0.06$ & 0.7 \\
UF PET (mL/4h) & $642 \pm 202$ & $645 \pm 260$ & 0.97 \\
\hline IPP (cmH $\left.{ }_{2} \mathrm{O}\right)$ & $7.1 \pm 3.6$ & $10.2 \pm 4.2$ & 0.02 \\
Sex ratio $(\mathrm{M} / \mathrm{W})$ & $12 / 9$ & $18 / 2$ & 0.03 \\
\hline
\end{tabular}

Figure 3-S. Clinical impact. Same as figure 3 but differentiating women with and without previous pregnancies. All women except 2 ( 1 with and 1 without previous pregnancies) increase ultrafiltration (UF) by increasing intraperitoneal volume (IPV). 


\section{Ultrafiltration with $1.5 \mathrm{~L}$ and $2.5 \mathrm{~L}(\mathrm{~mL})$}

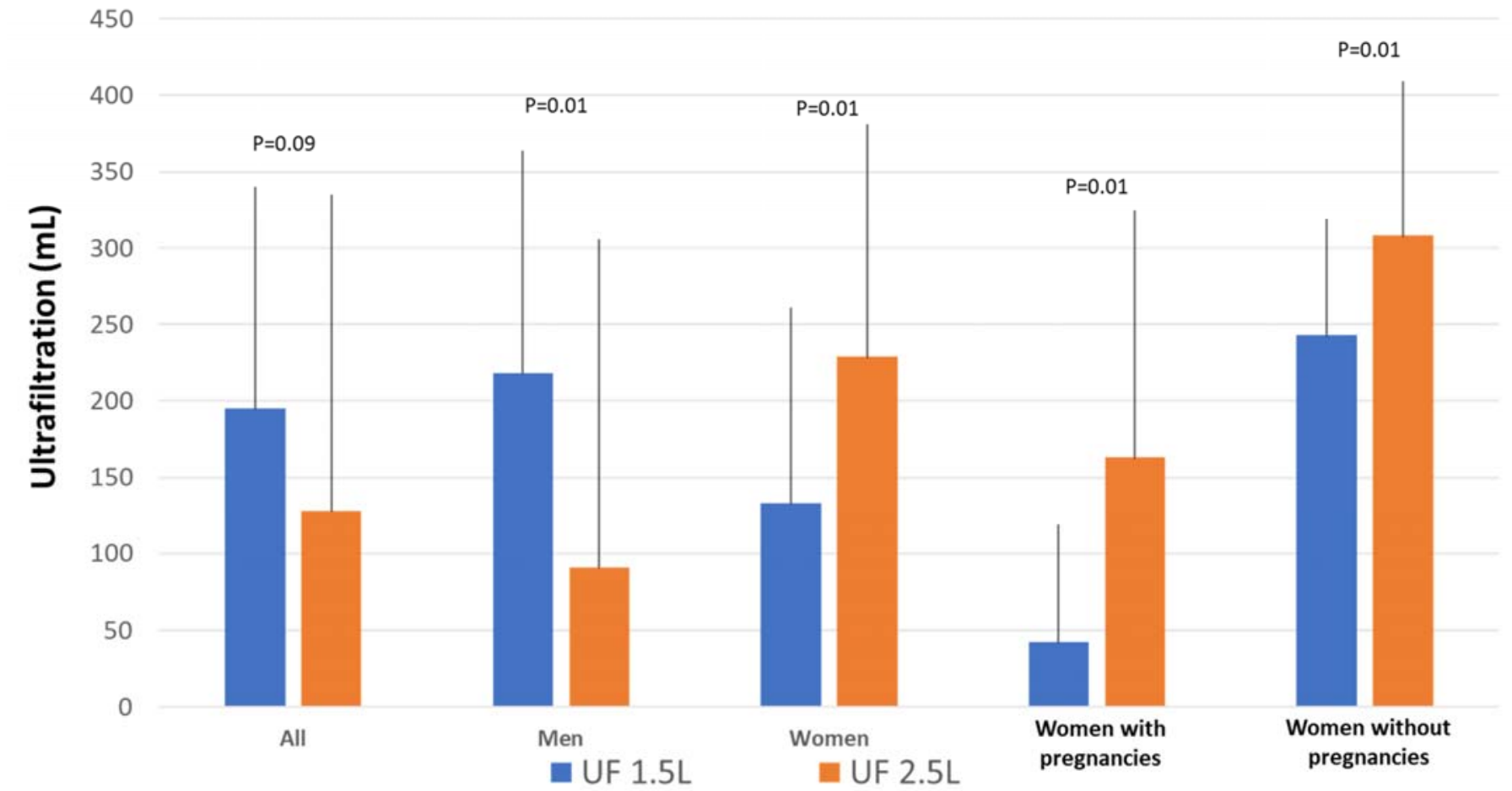

Figure 4-S. Ultrafiltration with $1.5 \mathrm{~L}$ and $2.5 \mathrm{~L}$ in men and women, and in women with and without previous pregnancies. 